\title{
Influence of storm sequencing on breaker bar and shoreline evolution in large-scale experiments
}

\author{
Sonja Eichentopf ${ }^{a, *}$, Joep van der Zanden ${ }^{\mathrm{b}, \mathrm{c}}$, Iván Cáceres ${ }^{\mathrm{d}}$, Tom E. \\ Baldock $^{\mathrm{e}}$, José M. Alsina ${ }^{\mathrm{d}}$ \\ ${ }^{a}$ Fluid Mechanics Section, Department of Civil and Environmental Engineering, Imperial \\ College London, London SW7 2AZ, UK \\ ${ }^{b}$ Marine and Fluvial Systems Group, University of Twente, Drienerlolaan 5, 7522 NB \\ Enschede, Netherlands \\ ${ }^{c}$ Offshore Department, Maritime Research Institute Netherlands, Haagsteeg 2, 6708 PM \\ Wageningen, Netherlands \\ ${ }^{d}$ Laboratori d'Enginyeria Marítima, Universitat Politècnica de Catalunya, 08034 \\ Barcelona, Spain \\ ${ }^{e}$ School of Civil Engineering, University of Queensland, Brisbane, Australia
}

\section{Abstract}

New large-scale experiments on the influence of storm sequencing on beach profile evolution are presented. The experiments comprised three sequences that commenced from the same initial beach profile. Each sequence consisted of two storms of different energy, with each storm followed by a recovery phase. A specific focus of the experiments was the influence of storm chronology as well as the influence of the recovery wave energy and duration on beach evolution. The breaker bar and the shoreline are studied as indicators for the beach response. Both evolve towards an equilibrium location for each wave condition where the breaker bar reaches its equilibrium much faster than the shoreline. Overall, no enhanced beach erosion due to storm

\footnotetext{
${ }^{*}$ Corresponding author.

Email address: sonja.eichentopf16@imperial.ac.uk (Sonja Eichentopf)
} 
sequencing is observed. Despite a similar cumulative wave power of the three sequences, the final beach configuration of each sequence seems to be determined by the last wave condition instead of previous storms. However, storm sequencing is important when the beach profile has not yet fully recovered before being disrupted by the subsequent storm. In this case, the second storm does not necessarily cause further erosion but can result in onshore sediment transport and hence, form part of the recovery. The bulk onshore sediment transport as well as the shoreline recovery rate vary depending on the wave condition and the profile disequilibrium and show a maximum value for a recovery condition with an intermediate wave energy. The very low energy condition that was performed for a long duration (24 hours) generated a near-stationary beach profile with typical features of a reflective beach.

Keywords: large-scale experiments, storm sequencing, beach recovery, beach equilibrium, sediment transport, reflective beach 


\section{Introduction}

Storms that arrive in close temporal succession (storm sequences) have been regarded to present a potentially underestimated risk for beaches as they may result in increased beach erosion. However, it is still not clear how the beach responds to a sequence of storms and whether a storm within a sequence leads to more severe erosion than the storm as an isolated event.

On the one hand, several studies found that storm sequences may lead to more severe beach erosion due to insufficient recovery time before the next storm makes landfall (e.g. Birkemeier et al., 1999; Cox and Pirrello, 2001; Ferreira, 2002, 2005; Karunarathna et al., 2014). In this regard, Birkemeier et al. (1999) proposed the 'destabilising hypothesis', suggesting that the early storms in a sequence destabilise the beach and therefore, the later storms result in more severe beach change than one would expect from their intensity. Karunarathna et al. (2014) studied circa 30 years of data from Narrabeen Beach, Australia, and found that storm sequences with a cumulative storm power (calculated as the sum of the power of all storms in a sequence) that was equivalent to the power of an individual storm resulted in larger beach erosion.

On the other hand, recent studies support an equilibrium beach concept stating that the beach, even under the influence of storm sequences, evolves towards an equilibrium state (e.g. Vousdoukas et al., 2012; Coco et al., 2014;

Morales-Márquez et al., 2018). Coco et al. (2014) found that due to severe beach erosion of a very energetic storm, a subsequent weaker storm had a limited erosive effect. They did not observe a cumulative erosive effect during the studied storm sequence. In line with beach equilibrium models 
(e.g. Miller and Dean, 2004; Yates et al., 2009), Vousdoukas et al. (2012) presented a conceptual model which states that, once the beach has reached an equilibrium, it is only eroded further if storm intensity or water levels of previous storms are exceeded.

However, this concept may not hold if there is a change of the beach state as it was reported by Baldock et al. (2017) and Birrien et al. (2018) for a large storm and subsequent lower energy wave conditions at Duck, N. C. and for medium-scale laboratory experiments. Waves with low energy following high energy conditions were found to break further onshore due to the previously eroded profile resulting in continued beach erosion under low energy conditions. In this case, a subsequent smaller storm can generate further erosion as the beach state is altered and a new equilibrium state develops for the same wave conditions.

Other studies, such as Ruiz de Alegría-Arzaburu and Vidal-Ruiz (2018), reported that, because of severe beach erosion and offshore sediment transport into larger water depths than usual during winter months, subsequent summer wave conditions were unable to fully recover the beach. This implies that a minimum level of wave energy is required to mobilise sediment that was transported far offshore during high energy storms (Scott et al., 2016; Ruiz de Alegría-Arzaburu and Vidal-Ruiz, 2018; Biausque and Senechal, 2019).

Overall, the number of studies available in the research field of storm sequencing and beach response is limited and most were based on field measurements or numerical simulations (e.g. Birkemeier et al., 1999; Ferreira, 2002, 2005; Castelle et al., 2008; Vousdoukas et al., 2012; Loureiro et al., 2012; Karunarathna et al., 2014; Splinter et al., 2014; Dissanayake et al., 
2015a,b,c; Angnuureng et al., 2017). These studies were usually linked to a specific field site and hence, the results may not be generically applicable. Field measurements are obtained under natural conditions where different aspects of storm sequence effects cannot be isolated and wave conditions cannot be controlled. In contrast, numerical models offer perfect control of the input storm sequencing. However, they require extensive calibration, accumulate numerical errors during simulation time (which is critical for long sequences) and they show rather poor performance when it comes to modelling recovery phases (van Rijn et al., 2011). Moreover, only few studies on storm sequence effects accounted for recovery conditions, (e.g. Ranasinghe et al., 2012; Pender and Karunarathna, 2013; Karunarathna et al., 2014; Gravois et al., 2018), while most studies neglected recovery between storms (Ferreira, 2002, 2005; Splinter et al., 2014; Dissanayake et al., 2015a,b,c; Gravois et al., 2016), especially those where process-based numerical models were used.

Compared to field measurements and numerical simulations, laboratory experiments have not commonly been used to study the effects of storm sequences on beach evolution (Eichentopf et al., 2019a). This can be related to the large resources, especially in terms of time and capital, required to perform long sequences of alternating high and low energy wave conditions. Laboratory experiments allow the performance of controlled and pre-defined storm sequence conditions and detailed temporal-spatial measurements of beach profile evolution and hydrodynamic parameters. It needs to be noted that controlled experiments are normally a representation of real conditions which present a simplification. Gravois et al. (2016) presented one of the few laboratory studies on storm sequence effects on beaches comprising medium- 
scale experiments with two storms of different intensity performed in different orders. Their study highlighted the importance of a very energetic storm within a sequence which resulted in a similar beach profile regardless of the initial beach state. Like most studies on storm sequences, Gravois et al. (2016) did not account for low energy conditions between storms, which could have the capacity to recover the beach.

Likewise, previous large-scale laboratory experiments primarily focussed on high energy (storm) wave conditions. The experiments usually comprised one high energy (storm) event and only in a few studies was a low energy (recovery) phase performed after the storm (Eichentopf et al., 2018). If recovery phases were performed, they were usually of limited duration even though beach recovery may take more time and hence, the development of a well recovered beach has not commonly been observed in large-scale experiments. Although insightful, laboratory data with only one storm followed by a recovery phase do not allow the investigation of storm sequence effects on beaches due to the potential influence of the previous beach state on future storms where specific beach profile parameters might be in disequilibrium.

Previous studies highlighted the importance of the initial beach morphology for beach evolution towards equilibrium (Yates et al., 2009; Baldock et al., 2017; Morales-Márquez et al., 2018). They reported that, although the equilibrium beach profile depends only on the wave forcing, reaching the same equilibrium profile from different initial beach profiles and same wave conditions results in different rates of beach change and sediment transport. Yates et al. (2009) showed that, depending on the antecedent beach state, the same wave condition can result in either accretion of a previously eroded 
beach or in erosion of a previously accreted beach. Similar observations were made by Scott et al. (2016) and Biausque and Senechal (2019). In addition, Yates et al. (2009) found that change rates of the beach were higher for a larger disequilibrium of the beach for the prevailing wave conditions.

Despite the increasing number of studies comprising storm sequences, their effect on beach erosion and the role of recovery are still not well understood. This is, at least partly, attributed to the lack of data with high temporal-spatial resolution of beach profile evolution during storm sequence conditions. In this regard, physical modelling presents a powerful tool as it allows the performance of controlled wave conditions and detailed measurements. An improved understanding of beach evolution during storm sequences may ultimately be valuable for a better assessment of coastal risks.

In this paper, we investigate the effects of storm sequences on cross-shore beach profile evolution. Specific objectives are to study the effects of storm chronology and the effect of recovery conditions on beach response. This study is based on beach profile measurements, wave breaking observations and sediment samples obtained in recently performed large-scale morphodynamic experiments. These experiments resulted in one of the first largescale data sets comprising multiple storm and recovery stages within the same test sequence. The performed wave conditions were unidirectional and shore-normally approaching allowing the investigation of cross-shore beach morphodynamics. The prominent parameters - breaker bar location, shoreline location and sediment transport - will be used as indicators for beach response.

This paper is organised as follows. Section 2 and 3 describe the ex- 
perimental set-up and the data analysis, respectively. Results of the beach evolution, with a specific focus on breaker bar and shoreline evolution, as well as sediment transport are presented in section 4. The discussion and conclusions follow in sections 5 and 6 , respectively.

\section{Experimental set-up}

The data in this study were obtained within the EU funded HYDRALAB ${ }^{+}$Transnational Access project RESIST ('Influence of storm sequencing and beach $\underline{R E c o v e r y ~ o n ~} \underline{S} e d \underline{I}$ ment tran $\underline{\text { Spor }} \underline{\mathrm{T}}$ and beach resilience'). For a detailed description of the experimental set-up the reader is referred to Eichentopf et al. (2019b); in this section, the most relevant aspects regarding the wave flume, the measurements and the wave conditions for the present study are outlined.

\subsection{Wave flume and instrumentation}

The experiments were performed in the large-scale wave flume Canal d'Investigació i Experimentació Marítima (CIEM) at Universitat Politècnica de Catalunya (UPC) in Barcelona, Spain. The CIEM is $100 \mathrm{~m}$ long, $3 \mathrm{~m}$ wide and $4.5 \mathrm{~m}$ deep and hence, is one of the few facilities for large-scale testing of waves and beach profile evolution (see Dette et al., 2002; Eichentopf et al., 2018, for an overview of large-scale wave flumes and available data). In the CIEM, waves are generated by a wedge-type wakemaker for which steering signals are based on first-order wave generation. Active absorption was not used as reflection of the short wave is minimal because of wave breaking energy dissipation at the beach slope. In addition, the long wave components are of low frequencies for which active absorption is known to be less 
effective (Baldock et al., 2000). Seiching and spurious waves associated with first-order wave generation are addressed in section 2.2 .

The water depth at the wave paddle was $2.5 \mathrm{~m}$. The experiments started from a handmade 1/15 sloped beach profile created by commercial sand. As known from previous sieving analysis, the sand had a narrow grain size distribution with $d_{50, \text { siev }}=0.25 \mathrm{~mm}\left(d_{10, \text { siev }}=0.154 \mathrm{~mm}\right.$ and $\left.d_{90, \text { siev }}=0.372 \mathrm{~mm}\right)$ and a measured sediment settling velocity of $w_{s}=0.034 \mathrm{~m} / \mathrm{s}$.

Two stainless metal plates (dividers) of $3 \mathrm{~mm}$ width, $6 \mathrm{~m}$ length and $0.7 \mathrm{~m}$ height were placed in the inner surf and swash zone to reduce cross-tank asymmetries that usually occur at the run-up end. Baldock et al. (2017) installed similar dividers in their medium-scale wave flume experiments and successfully reduced cross-tank flow and bed level asymmetries. Similar to Baldock et al. (2017), the dividers were self-supporting through burial within the beach before the start of the wave runs. They divided the flume into three sections of circa $0.75 \mathrm{~m}, 1.5 \mathrm{~m}$ and $0.75 \mathrm{~m}$ width in sequence 1 . After the first sequence, the dividers were slightly moved towards the centre of the flume to improve their effect so that the flume was then divided into three equal widths of circa $1 \mathrm{~m}$.

The beach profile was measured along the centre line of the flume with a mechanical profiler that is capable of measuring the profile depth in the emerged as well as in the submerged part of the beach. The bed profile measurements had a spatial resolution $\Delta x=0.02 \mathrm{~m}$ and a vertical accuracy of $0.01 \mathrm{~m}$ (Baldock et al., 2011). During the first 5-10 min of each wave test, visual observations of the most offshore (outer) and most onshore (inner) breaking location as well as the location of maximum wave run-up and run- 
down were noted. After completion of the entire measuring programme, sediment samples were collected from the bed of the drained flume at 20 cross-shore locations in the surf and swash zones with a typical spacing of $0.5 \mathrm{~m}$ or $1.0 \mathrm{~m}$. These samples were collected after performing a very low energy wave condition for a very long duration and were used to investigate the sorting of sediment at the end of the sequence (see section 3.3 for details of the analysis technique).

The experiments present large-scale conditions which are considered to be near full scale and which are generally less affected by scaling (SánchezArcilla et al., 2011). In a previous measuring campaign (SANDS project (see Cáceres et al., 2008)), beach profile evolution in the same wave flume was compared to prototype conditions (GWK wave flume in Hannover, Germany) applying undistorted geometric and Froude scaling with a geometric scale relationship of approximately 1:2. The results showed very good agreement of the beach profile evolution between the different flumes (Sánchez-Arcilla et al., 2011) which means that the results correspond to a geometric scaling relation of approximately $1: 2$.

\subsection{Storm sequences and wave conditions}

In the present experiments, three storm sequences were generated. Each sequence commenced from the $1 / 15$ bed profile and consisted of two storms (energetic wave conditions) with each storm followed by a low energy phase. Based on experience from previous experiments, the high and low energy wave conditions were anticipated to present phases of beach erosion and accretion, respectively.

Most of the performed wave conditions are bichromatic waves which rep- 
resent repeatable wave groups. Repeatable wave conditions are essential for the analysis of sediment concentration and associated hydrodynamic data that were acquired in the RESIST experiments and that have been investigated in accompanying publications (e.g. van der Zanden et al., 2019). In terms of beach profile evolution, Baldock et al. (2011) showed for experiments in the same flume that sediment transport and beach response under bichromatic waves is similar to random waves of the same energy, in contrast to the sediment transport by monochromatic waves.

Table 1 summarises details of the wave conditions, including the target root mean square wave height $H_{r m s}(\mathrm{~m})$, the mean primary wave period $T_{p}(\mathrm{~s})$ (calculated as the inverse of the mean primary wave frequency $f_{p}=\left(f_{1}+\right.$ $\left.f_{2}\right) / 2$ ) for bichromatic wave conditions and the peak period for random wave conditions, and the dimensionless sediment fall velocity $\Omega=H_{r m s} /\left(w_{s} T_{p}\right)$. The wave heights and frequencies of the two bichromatic wave components (specified by the indices), as well as the bichromatic wave group period $T_{g r}=$ $1 /\left(f_{1}-f_{2}\right)$ are also shown in table 1 . The energetic wave conditions repeated every two wave groups, whereas the low energy conditions repeated every three groups. Low energy conditions were partly modulated with $\mathrm{H}_{1}=0.5 \mathrm{H}_{2}$ to facilitate continuous sediment entrainment for the low energy conditions which was important for the quality of the suspended sediment and velocity measurements in the RESIST experiments (investigated in accompanying studies). $\Omega$ has traditionally been used to determine the overall tendency of a beach (erosion or accretion) under a given wave climate (Gourlay, 1968; Dean, 1973; Dalrymple, 1992). E1 and E2 denote the storm wave conditions, where E1 presents a highly energetic storm and E2 a lower energy storm. A1, 
A2 and A3 are low energy wave conditions, which are anticipated to recover the beach and of which A3 presents the least energetic condition.

Wave condition B presents a benchmark case which was performed for 30 min at the start of each sequence in order to compact and homogenise the manually reshaped bed. In the benchmark case, random waves with a Jonswap spectrum with $\gamma=3.3$ were performed.

A standing wave due to basin seiching at a frequency of $f \approx 0.024 \mathrm{~Hz}$ was observed after each test. This is close to the frequency of the seiching wave that was previously reported from data obtained in the same wave flume but with different wave conditions (Alsina and Cáceres, 2011; van der Zanden et al., 2018). Spectral analysis of the water surface signal measured at circa $11.8 \mathrm{~m}$ from the wave paddle revealed typical amplitudes of $<0.5 \mathrm{~cm}$ at this frequency, which is considered small compared to the amplitudes at the short wave and wave group frequencies. For bichromatic waves, the energy transfer between the wave components is well-defined (e.g. Alsina et al., 2016) and the bichromatic wave components and their combinations have been designed not to coincide with the seiching mode and therefore, the non-linear wave energy transfer to the seiching mode is very small. Spurious free long waves at the wave group frequency may also occur due to limitations of the first-order wave generation by the wave paddle and the absence of an active wave absorption system for long waves. For experiments in the same wave flume and involving bichromatic waves, Alsina et al. (2016) reported that free ingoing long waves represented up to $27 \%$ of the total energy at the group frequency. In addition, they found that changes in the breaker bar location were explained by variations in the breaking location with negligible 
influence of long waves. Therefore, the effect of seiching and incident spurious long waves on short wave propagation, wave breaking and the morphological evolution is expected to be small.

\begin{tabular}{|c|c|c|c|c|c|c|c|c|c|c|}
\hline \multicolumn{3}{|c|}{ Wave condition } & $H_{r m s}(\mathrm{~m})$ & $T_{p}(\mathrm{~s})$ & $\Omega(-)$ & $H_{1}(\mathrm{~m})$ & $H_{2}(\mathrm{~m})$ & $f_{1}(\mathrm{~Hz})$ & $f_{2}(\mathrm{~Hz})$ & $T_{g r}(\mathrm{~s})$ \\
\hline B & Benchmark & Random & 0.30 & 4 & 2.21 & $\mathrm{n} / \mathrm{a}$ & $\mathrm{n} / \mathrm{a}$ & $\mathrm{n} / \mathrm{a}$ & $\mathrm{n} / \mathrm{a}$ & $\mathrm{n} / \mathrm{a}$ \\
\hline E1 & High energy 1 & Bichromatic & 0.42 & 3.7 & 3.34 & 0.320 & 0.320 & 0.3041 & 0.2365 & 14.80 \\
\hline E2 & High energy 2 & Bichromatic & 0.32 & 3.7 & 2.54 & 0.245 & 0.245 & 0.3041 & 0.2365 & 14.80 \\
\hline A1 & Low energy 1 & Bichromatic & 0.23 & 4.7 & 1.44 & 0.101 & 0.202 & 0.2276 & 0.1979 & 33.68 \\
\hline A2 & Low energy 2 & Bichromatic & 0.19 & 5.3 & 1.05 & 0.085 & 0.171 & 0.2018 & 0.1755 & 37.98 \\
\hline A3 & Low energy 3 & Bichromatic & 0.14 & 5.7 & 0.72 & 0.063 & 0.126 & 0.1877 & 0.1632 & 40.85 \\
\hline
\end{tabular}

Table 1: Target wave conditions performed in the RESIST experiments.

The different wave conditions were combined to form three sequences of storms as summarised in table 2. Sequences 1 and 2 comprised the same wave conditions for the same duration where only the chronology of the storms was reversed. In sequences 1 and 2, only one type of low energy wave condition was performed for the same duration (A1 for $600 \mathrm{~min}$ ). In sequence 3 , the storm chronology was the same as in sequence 1 (first E1, then E2) but the low energy conditions were different: A2 was performed for 780 min (=13 hours) after E1 and A3 was performed for $1440 \mathrm{~min}$ (=24hours) after E2. These durations were chosen to have a similar time-integrated offshore wave power for all low energy conditions which consequently means a highly similar total (cumulative) offshore wave power for all three sequences. The time-integrated offshore wave power $P(\mathrm{kWh} / \mathrm{m})$ for each wave condition is obtained as: 


$$
P=\frac{1}{32 \pi} \rho g^{2} H_{0, r m s}^{2} T_{p} \Delta t
$$

where $\Delta t$ presents the duration of the wave condition, $H_{0, r m s}$ is the calculated corresponding offshore root mean square wave height, $g\left(\mathrm{~m} / \mathrm{s}^{2}\right)$ is the gravitational acceleration and $\rho\left(\mathrm{kg} / \mathrm{m}^{3}\right)$ the density of water (taken as the density of fresh water as $1000 \mathrm{~kg} / \mathrm{m}^{3}$ ). The cumulative offshore wave power $P_{\text {cum }}$ of each sequence (calculated as the sum of $P$ of the different wave conditions) is also shown in table 2 . The 20 sediment samples (mentioned above in section 2.1) were collected after the end of the last sequence; hence, after condition A3.

\begin{tabular}{ccc|ccc|ccc}
\multicolumn{3}{c|}{ Sequence 1 } & \multicolumn{3}{|c|}{ Sequence 2 } & \multicolumn{4}{|c}{ Sequence 3 } \\
Condition & Duration $(\mathrm{min})$ & $P_{\text {cum }}(\mathrm{kWh} / \mathrm{m})$ & Condition & Duration $(\mathrm{min})$ & $P_{\text {cum }}(\mathrm{kWh} / \mathrm{m})$ & Condition & Duration $(\mathrm{min})$ & $P_{\text {cum }}(\mathrm{kWh} / \mathrm{m})$ \\
\hline B & 30 & 0.19 & B & 30 & 0.19 & B & 30 & 0.19 \\
E1 & 240 & 3.16 & E2 & 120 & 1.06 & E1 & 240 & 3.16 \\
A1 & 600 & 5.68 & A1 & 600 & 3.58 & A2 & 780 & 5.63 \\
E2 & 120 & 6.55 & E1 & 240 & 6.55 & E2 & 120 & 6.50 \\
A1 & 600 & 9.07 & A1 & 600 & 9.07 & A3 & 1440 & 9.04
\end{tabular}

Table 2: Storm sequences with their wave conditions, duration and cumulative timeintegrated offshore wave power.

Wave conditions were performed in tests of $30 \mathrm{~min}$ or $60 \mathrm{~min}$ after which the wave paddle was stopped to measure the beach profile during still water conditions. Usually, the first $120 \mathrm{~min}$ of each wave condition were performed as $30 \mathrm{~min}$ tests to ensure more frequent profile measurements during the anticipated fast changing initial stage of beach profile evolution. Conditions A2 and A3 were performed only as 60 min tests due to anticipated slow rate 
of beach profile change.

Beach profiles were measured before the start of each sequence (initial profile) and after each test. Most profiles were measured between circa $53.5 \mathrm{~m}$ and $87 \mathrm{~m}$ onshore of the wave paddle $(87 \mathrm{~m}$ is onshore of the maximum wave run-up) and were supposed to cover the entire active beach. An extended ('complete') profile measurement starting at $40 \mathrm{~m}$ onshore of the wave paddle was obtained before the start and at the end of each sequence. In addition for sequences 2 and 3, a complete profile measurement was obtained upon completion of each wave condition.

These measurements resulted in a total number of 119 beach profiles. Two profile measurements had to be discarded (one after condition B and one during E1 in sequence 1) due to acquisition errors.

\subsection{Coordinate system and initial beach profile}

The coordinate system used in the present study has its cross-shore origin at the initial shoreline (intersect of the still water level with the initial profile) of each sequence. The cross-shore variable $x$ is defined positive landward. The vertical variable $z$ has its origin at the still water level, positive upwards.

The first wave condition of each sequence started from a handmade initial 1/15 sloped beach profile. Figure 1 compares the variability between the initial beach profiles. The top panel (figure 1a) shows the mean of the three initial profiles and the profile envelope (minimum and maximum of the three profiles at each $x$-location); the bottom panel (figure $1 \mathrm{~b}$ ) shows the difference of the profile envelope. The initial profiles are found to be highly similar with a mean difference in the profile envelope of $<3 \mathrm{~cm}$ (standard deviation of $1.8 \mathrm{~cm})$. 

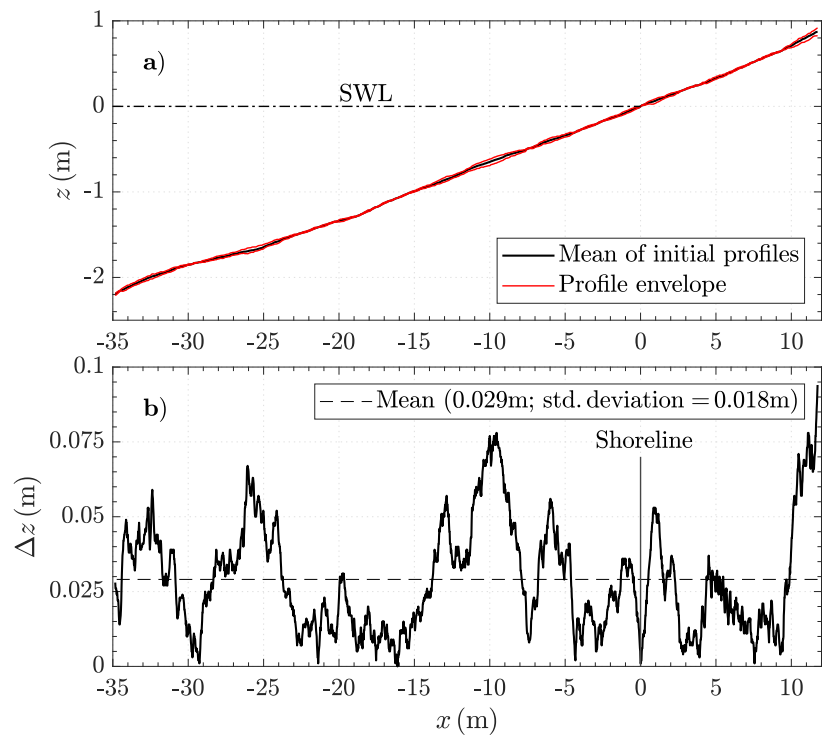

Figure 1: a) Mean initial profile and envelope, still water level (SWL) $(-\cdot-)$; b) Difference of profile envelope and mean difference.

\section{Data analysis}

In this section, the definition of the bar and shoreline location, the calculation of sediment transport as well as the analysis of sediment samples in terms of sediment grain size distribution are presented.

\subsection{Shoreline and bar definition}

In this work, the shoreline and the breaker bar location are studied as indicators for the beach response. Both can be defined for each measured beach profile. The definition of these parameters is illustrated in figure 2 . The shoreline location $x_{0}$ is the cross-shore location where the still water level (SWL) intersects the profile, which presents a well-defined and common approach to define the shoreline location in laboratory experiments (e.g. 
Grasso et al., 2011; Sánchez-Arcilla et al., 2011; Baldock et al., 2017; Eichentopf et al., 2018). Shoreline erosion (recovery) is defined as how much the shoreline recedes (accretes) in the cross-shore direction during a defined time interval.

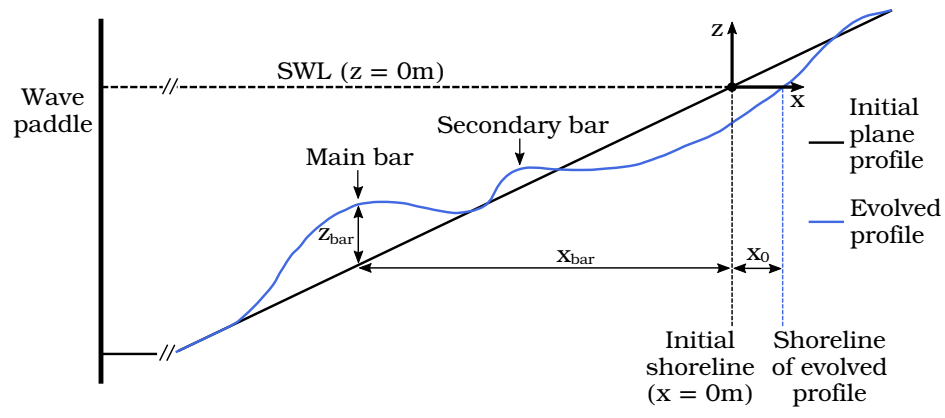

Figure 2: Definition of coordinate system that refers to the initial shoreline and definition of profile/bar parameters.

The breaker bar location $x_{b a r}$ is defined as the cross-shore location of the maximum difference in elevation between the studied and the initial beach profile ('global maximum elevation'), hereinafter also named 'main (breaker) bar' (following e.g. Alsina et al., 2012; Eichentopf et al., 2018). A smaller, secondary bar can form onshore or offshore of the breaker bar under some wave conditions. This secondary bar is defined as the second largest local elevation difference (see figure 2).

\subsection{Sediment transport computations}

The sediment transport rate $q\left(\mathrm{~m}^{2} / \mathrm{s}\right)$ at each cross-shore location $x_{i}$ is obtained from the change in bed elevation $\Delta z_{i}$ during a corresponding time interval $\Delta t$ (Baldock et al., 2011): 


$$
q\left(x_{i}\right)=q\left(x_{i-1}\right)-\int_{x_{i-1}}^{x_{i}}(1-p) \frac{\Delta z_{i}}{\Delta t} d x
$$

where $p(-)$ is the porosity of the sediment bed which equals 0.4. $q$ presents the total (bed load and suspended load) sediment transport rate which is offshore directed for negative values of $q$ and onshore directed for positive values of $q$.

At both cross-shore boundaries of the sediment transport computation (closure limits), the sediment transport rate computed by eq. (2) should be zero as no sediment is transported beyond these limits. However, as known from previous studies (e.g. Baldock et al., 2010, 2011; Gravois et al., 2016), $q$ obtained from eq. (2) is often not equal to zero at the offshore closure limit which is primarily related to the accuracy of the profile measurements as well as to the profile not being perfectly uniform across the flume. To ensure the condition of zero sediment transport at the closure limits is met, any error in sediment volume when computing sediment transport is distributed uniformly along the profile (following Baldock et al., 2010, 2011).

A parameter to analyse the beach response during any time interval $\Delta t$ is the net bulk transport $Q\left(\mathrm{~m}^{3}\right)$ obtained as the integral of $q$ along the profile (Baldock et al., 2011, 2017; Jacobsen and Fredsoe, 2014):

$$
Q=\Delta t \int_{x_{\min }}^{x_{\max }} q(x) d x
$$

where $x_{\min }$ and $x_{\max }$ present the off- and onshore boundaries, respectively, past which no sediment transport occurs. $Q$ is non-zero if there is a net movement of the sediment mass within the active profile, even though the total volume of sediment is conserved. 
$Q$ has been used as an indication of the overall beach response (erosive or accretive) where positive values of $Q$ present net onshore sediment transport (beach accretion) and negative values of $Q$ refer to net offshore sediment transport (beach erosion). $Q$ can be computed for different time intervals (in the present study this is normally the time under the same wave conditions) and is supposed to approach a stable value (equilibrium) after sufficiently long performance of the same wave condition.

\subsection{Analysis of sediment grain size distribution}

The grain size distribution of the sediment samples that were collected from the bed after completion of wave condition A3 were analysed by means of the laser-based imaging system QICPIC developed by Sympatec GmbH. A description of the system can be found in Altuhafi et al. (2013). Sieving of the original samples was performed to remove sediment grains $<100 \mu \mathrm{m}$ which is outside the measuring range of QICPIC (Altuhafi et al., 2013). This fraction was very small in all the samples (normally $<1 \%$ ) and was taken into account when post-processing the sediment grain size data obtained with QICPIC.

From QICPIC, several particle size measures are available. Results from conventional sieving analysis showed to be closest to the minimum Feret diameter (minimum distance between two parallel tangents on opposite sides of the particle) which is consistent with Altuhafi et al. (2013). Therefore, the minimum Feret diameter was used to compare the results at the different cross-shore locations. 


\section{Results}

In this section, results from the analysis of beach profile changes and sediment transport calculations are presented. First, the overall beach profile evolution during the three performed storm sequences is presented along with more details on the beach evolution under the two storm wave conditions and the recovery conditions of long duration. After this, the changes of the breaker bar and wave breaking location as well as the shoreline evolution during the three sequences are analysed. Finally, the results of the bulk sediment transport and sediment transport rates are presented.

\subsection{Beach profile evolution}

The overall evolution of the beach profile in the three sequences is shown in figure 3 as a contour plot. Profiles are presented as elevation changes $\Delta z_{0}$ between each profile and the initial profile. In figure 3 , the shoreline location is indicated as bold black line, the location of the breaker bar and the secondary bar of each profile are shown as solid and open circles, respectively.

In general, the three sequences present some similitudes during the high energy and low energy conditions of the different sequences. The high energy events result, in all sequences, in the generation of a breaker bar, its offshore migration and beach erosion in the inner surf zone (usually associated with shoreline retreat). Major beach profile changes during high energy wave conditions occur primarily in the beginning of these conditions, reaching a quasi-equilibrium situation within a few tests (typically within circa $90 \mathrm{~min}$ ).

The bar reaches its most offshore location during the most energetic (E1) condition. During E1, a secondary (inner) bar forms onshore of the main 


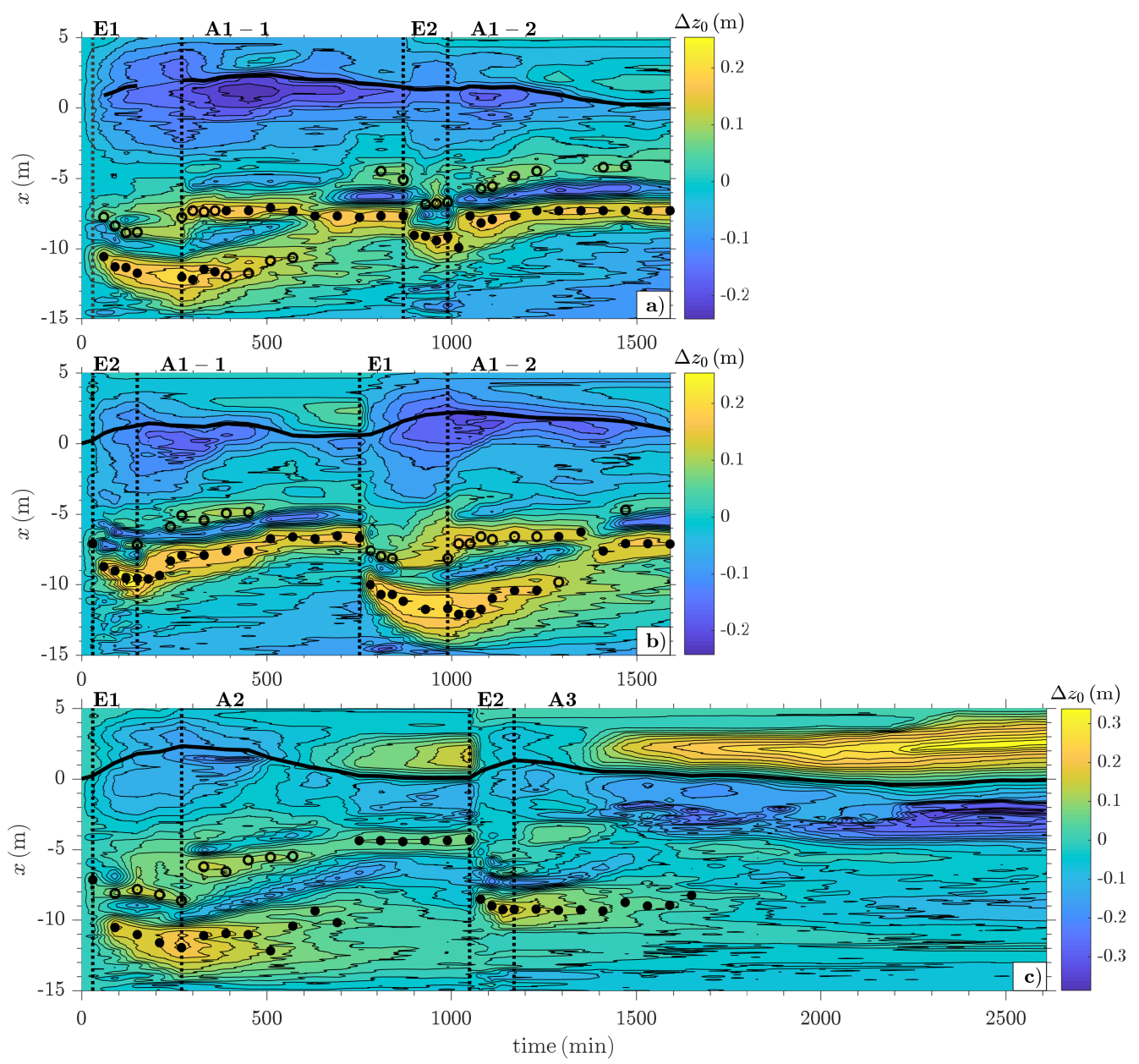

Figure 3: Contour plots of elevation changes $\Delta z_{0}$ from the initial profile over time in sequence 1 (a), sequence 2 (b) and sequence 3 (c). The shoreline $(\longrightarrow)$, breaker bar $(\bullet)$ and secondary bar location (o) are highlighted. Note that the breaker bar location could not be defined for two tests in sequence 1 because no profile measurements were available for these tests.

breaker bar and it also migrates offshore with increasing high energy test time. Processes driving secondary bar evolution have been addressed in previous studies. Pape et al. (2010) highlighted that, while most wave energy is 
dissipated over the outer bar, wave reformation and secondary wave breaking can be important for inner bar evolution; in addition, Baldock et al. (2017) reported that the sediment needed for secondary bar formation was drawn from the inner surf zone in both laboratory and field conditions.

The low energy wave conditions in the three sequences lead to onshore migration of the main breaker bar and recovery of the shoreline. Sediment movement during low energy conditions seems to occur more slowly than during energetic conditions and the low energy conditions reach a quasiequilibrium situation after longer timescales. Under low energy conditions, a berm develops in the swash zone while the trough at around $x \approx 0 \mathrm{~m}$ deepens. This berm is very pronounced under conditions A2 and A3 and smaller for conditions A1. Towards the end of the low energy conditions, the berm grows and expands towards the offshore. This evolution of the berm is relevant to the evolution of the shoreline which will be further examined in section 4.3 .

Figure 3 reveals that the final profile morphology varies between the sequences and seems to be determined by the last performed wave conditions rather than the storm history, even though the cumulative power of the three sequences was approximately the same (see table 2). This suggests that the cumulative power of a storm sequence does not necessarily give indication on the beach morphology at the end of the sequence; the final morphology rather depends on the final recovery condition and whether these were run for a sufficiently long duration to arrive at a stable state. 


\subsubsection{Storm wave conditions}

Figure 4 presents the beach profile evolution for the three sequences under conditions E1 (left panels) and E2 (right panels). Time intervals between the beach profile measurements are $60 \mathrm{~min}$ for $\mathrm{E} 1$ and $30 \mathrm{~min}$ for $\mathrm{E} 2$. The colour changes from light to dark as time progresses.

The formation of the breaker bar and its offshore migration can be clearly noted for both E1 and E2 as well as the formation and offshore migration of the secondary (inner) bar under E1. A trough develops in the inner surf/swash zone. The bar and trough have a larger volume under E1 than under E2. Offshore of the breaker bar, small profile changes in the form of ripples can be observed under E1 whereas under E2 measured beach profile changes appear to be negligible offshore of $x \approx-15 \mathrm{~m}$.

Most changes of the beach profile occur in the beginning of the high energy wave conditions. This can be noted, for instance, for condition E1 in sequence 2 (see figures $3 \mathrm{~b}$ and $4 \mathrm{c}$ ) where condition E1 presents an abrupt disruption to the beach profile resulting in erosion of the berm, the shoreline, and the bar. The bar gets almost entirely eroded within the first 30 min of condition E1 and a new bar appears closer to the equilibrium bar location of condition E1.

After these initially fast changes, the profile evolves towards a relatively stable state under both E1 and E2 which seems highly similar for each condition, despite the different profiles preceding the energetic conditions. This is in line with Gravois et al. (2016) who made similar observations in mediumscale experiments where an energetic event normally resulted in a highly similar final profile regardless of the initial profile of the storm wave condi- 

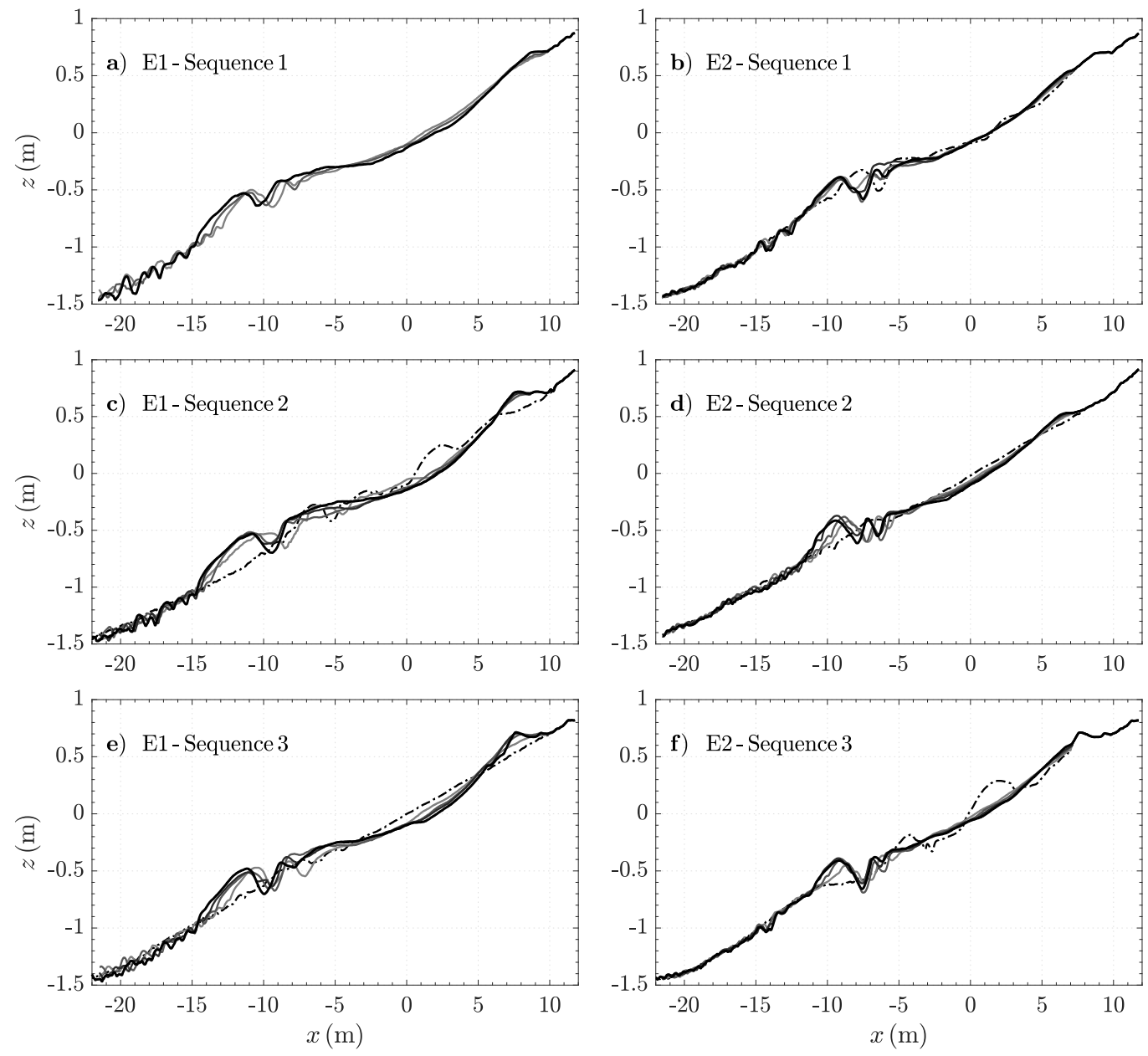

Figure 4: Profile evolution under high energy conditions E1 and E2 in the three sequences. Left (right) panels show profiles under E1 in 60 min intervals (under E2 in 30 min intervals); colour changes from light to dark as time progresses; dashed-dotted lines present the profile from which the energetic conditions started (this profile was not available for E1 sequence 1); the bold black line presents the last profile under the energetic conditions. Recall the order of the wave conditions in each sequence: sequence1 (E1-A1-E2-A1), sequence 2 (E2-A1-E1-A1), sequence 3 (E1-A2-E2-A3). 
tions. This suggests that the profile morphology from which the energetic storms start does not have a large influence on the profile morphology during and after this storm which is consistent with the equilibrium beach concept. It is noted that this finding might not hold in the case of an alteration of the beach volume, for instance by beach nourishments. Differences in the bar size and shoreline location were observed for the same storm conditions but different beach volumes and varying nourishment locations (Grasso et al., 2011).

\subsubsection{Low energy wave conditions of long duration}

In the presented experiments, conditions A2 and A3 present very long runs (13 h and $24 \mathrm{~h}$, respectively) of low energy wave conditions. Figure 5 shows selected beach profiles measured under conditions A2 and A3. The bar, that was formed during the preceding storm conditions, decays gradually under conditions A2 and A3 and only a small bar remains. At the end of conditions A2 and A3, the bar is no longer the most striking feature of the beach profile as a large berm has developed in the swash zone. The berm largely contributes to the recovery of the shoreline.

Of particular interest is the profile evolution observed under the low energy wave condition of very long duration (24 hours) in sequence 3 (condition A3). During A3, the sediment of the main breaker bar that evolved under E2 is transported onshore. This sediment volume spreads between $x \approx$ $10 \mathrm{~m}$ and $x \approx-2 \mathrm{~m}$ and it supplies the evolving berm resulting in a reflective beach state. Onshore transport of the bar sediment under long periods of low energy wave conditions has also been reported from field measurements (Phillips et al., 2017; Ruiz de Alegría-Arzaburu and Vidal-Ruiz, 2018). In 
addition, Phillips et al. (2017) and Ruiz de Alegría-Arzaburu and Vidal-Ruiz (2018) reported welding of the bar to the shoreline and highlighted the importance of the proximity of the bar to the shoreline for shoreline recovery. Even though in the present study the proximity of the breaker bar to the shoreline cannot clearly be linked to beach recovery and welding of the bar to the shoreline is not observed, onshore transport of the bar sediment under low energy conditions clearly takes place and the sediment is important to supply the formation of the berm, to recover the shoreline and to form a reflective beach profile.

Reflective beaches typically develop under wave conditions with very low $\Omega$ with the following characteristic features (Wright and Short, 1984; Short, 1999):

- an (almost) barless profile;

- a steep and relatively linear beach face with a runnel (the beach slope at the offshore side of the berm was $1 / 8$ which is considerably steeper than the $1 / 15$ slope of the initial profile);

- step formation at the base of the beachface (corresponding to the maximum run-down location which was observed to be located at $-1.8 \mathrm{~m}$ during the last A3 test, see figure 5b); and

- cross-shore sediment sorting with accumulation of coarser sediments around the step and deposition of finer sediments offshore of it.

In the present study, cross-shore sediment sorting was investigated based on the sediment samples that were collected from the drained flume after 

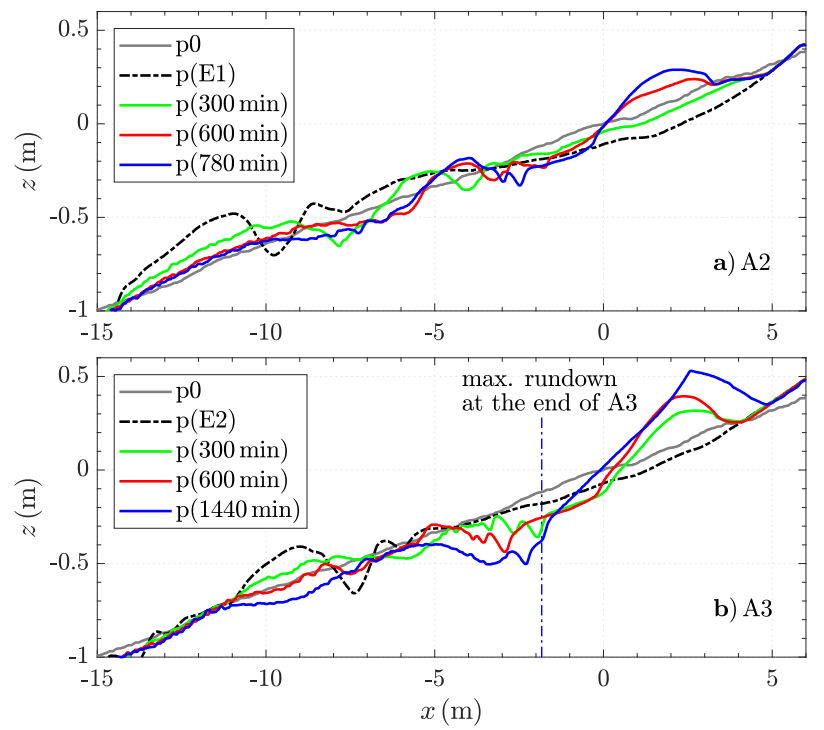

Figure 5: Berm formation and bar decay during A2 and A3 in sequence 3 (E1-A2-E2-A3). The indicated times refer to the time under the same wave condition.

completion of condition A3. Results from the sediment size analysis $\left(d_{10}, d_{50}\right.$, $\left.d_{90}\right)$ at the different cross-shore locations are shown in figure 6 along with the initial profile of the sequence and the final profile which was measured after A3.

A local accumulation of coarser sediments at the maximum rundown location at the end of A3 (corresponding to the location of the beach step) can be observed. Especially $d_{90}$ is large, reaching $0.58 \mathrm{~mm}$, and is indicative of the much wider grain size distribution around the beach step than at other locations. Directly onshore of the step, the sediment is finer and more uniformly distributed. Further onshore, around the shoreline, the sediment is again coarser and becomes finer with a more uniform distribution towards the crest of the berm. Apparently, only fine grained material is transported landward to the crest of the berm, while the coarse material tends to con- 


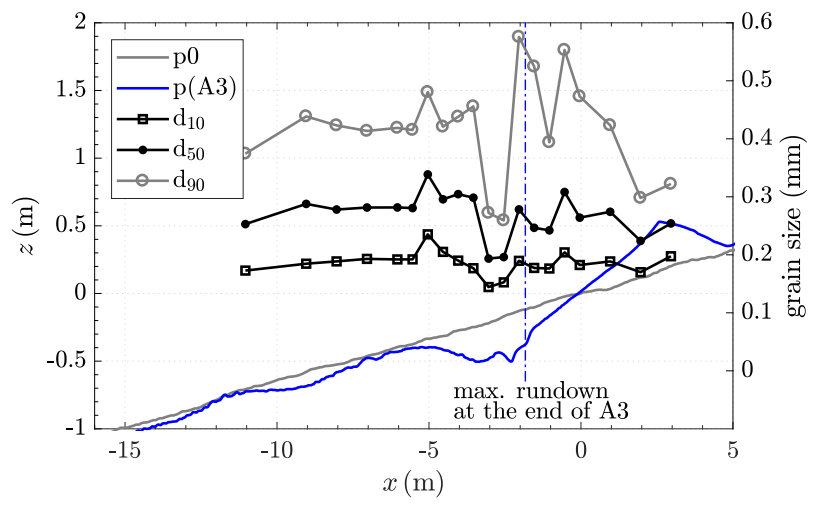

Figure 6: Initial and final beach profile as well as cross-shore distribution of grain sizes after condition A3 in sequence 3 (E1-A2-E2-A3). The left and right ordinate refer to the profile depth and to the grain size, respectively. The sediment diameters are taken as the minimum Feret diameter.

verge at the step which is in line with previous studies on graded sediment transport around beach steps, such as Miller and Zeigler (1958) and Hughes and Cowell (1987). Directly offshore of the step, the sediment is considerably finer with a very narrow grain size distribution. Towards the offshore, sediment sizes are relatively constant with increased sediment sizes at the crest of the decayed bar.

It needs to be noted that the sediment distribution at the beginning of condition A3 is unknown and hence, its effect cannot be taken into account. However, due to the long duration of A3 (24 hours) which resulted in a relatively steady profile state (see figures 3 ), the sediment distribution is assumed to have also reached a quasi-equilibrium condition that is specific for condition A3.

The results are generally in line with Masselink et al. (2016) who reported sorting of sediment during low energy conditions in large-scale morphody- 
namic experiments. In their experiments, the sediment became relatively fine towards the berm crest and relatively coarse in the mid-lower swash and inner surf zone which matches well with the results presented in figure 6 . However, Masselink et al. (2016) did not focus on the evolution of a reflective beach state and hence, did not report formation of a beach step and associated sediment sorting.

\subsection{Breaker bar migration and wave breaking location}

Figure 7 shows the locations of the breaker bar and the secondary bar together with the observed locations of inner and outer wave breaking for the three storm sequences. The figure reveals that both the outer and inner breaking location are found further offshore (onshore) for the more (less) energetic wave conditions. The wave breaking location usually changes immediately with the change in wave conditions and is often not much affected by the existing bar as will be detailed below. Overall, wave breaking oc-

curs at a very similar location for each wave condition. No wave breaking locations could be recorded towards the end of condition A3 because waves were identified from visual observations to be predominantly surging breakers which are typical of reflective beaches (Short, 1999).

Figure 7 shows a clear link between the breaker bar location and the outer breaking location. Under energetic wave conditions, the bar shows fast offshore migration to the outer breaking location directly at the beginning of the energetic conditions. The link between the bar and the breaking location, especially under high energy waves, corroborates findings from previous studies (e. g. Hoefel and Elgar, 2003; Mariño-Tapia et al., 2007; Almar et al., 2010; Pape et al., 2010; Eichentopf et al., 2018). Under subsequent 

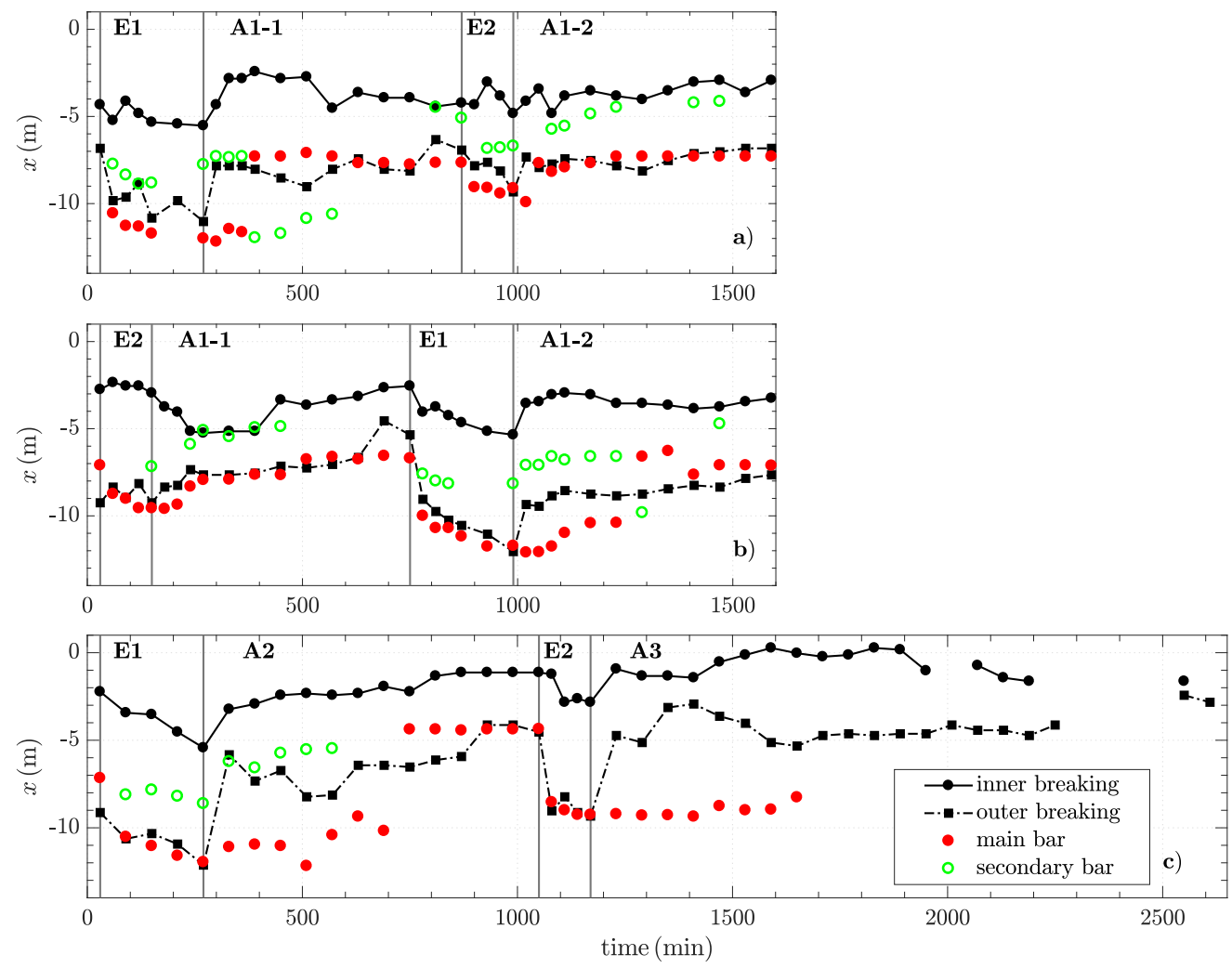

Figure 7: Observed breaking and computed bar location of sequence 1 (a), sequence 2 (b) and sequence 3 (c). Cross-shore location of outer breaking $(\rightarrow--)$, inner breaking $(\rightarrow \bullet)$, breaker bar $(\bullet)$, secondary bar $(\circ)$.

low energy conditions, the bar also migrates towards the outer breaking location but the timescale of migration is generally longer than for the high energy waves. Larger beach response times for lower energy wave conditions were also reported in previous studies comprising field measurements, such as Pape et al. (2010) and Morales-Márquez et al. (2018). During long periods of low energy waves, such as condition A3 in the present experiments, breaker bars do not necessarily travel towards the wave breaking location but they migrate onshore and eventually disappear (Pape et al., 2010). 
Under low energy conditions after E1, the secondary (inner) bar plays an important role for the bar to arrive at its equilibrium location. The waves are usually so small that they pass the breaker bar and break close to the secondary bar. This was similarly reported in previous studies, such as Baldock et al. (2017), Birrien et al. (2018) and Eichentopf et al. (2018). The secondary (inner) bar progressively increases in height until it turns into the main breaker bar. The outer bar gradually decreases in height and disappears under condition A2. Under condition A1, the outer bar migrates onshore while the location of the inner bar remains stable and the two bars eventually merge (see also figure 3a,b).

This observation may lead to a general reconsideration regarding the definition of the breaker bar in case of a multi-barred beach profile. Usually, the breaker bar is defined from the beach profile by either the maximum elevation change (as in the present study and e.g. Alsina et al., 2012, 2016; Eichentopf et al., 2018) or by the local maximum of the absolute profile (e. g. Sánchez-Arcilla and Cáceres, 2017). However, in the case of multiple bars, it appears more suitable to define an 'active breaker bar' (following Birrien et al., 2018) as the one which is closest to the outer breaking location rather than defining a 'main breaker bar' which is solely defined from the profile measurements.

After the initial adjustment of the bar to the outer breaking location, the bar is found at a relatively stable location with very limited changes ('quasiequilibrium location') under all wave conditions (given that a breaker bar could be defined). This is particularly evident for the low energy conditions A1 and A2 and it seems to be mainly a matter of time when the bar reaches 
a stable location. Under high energy waves, the bar also evolves towards a stable location as can be noted by the reduced offshore migration rate of the bar at the end of conditions E1 and E2.

To compare the quasi-equilibrium bar location at the end of the same wave condition, figure 8 shows the final bar location of each wave condition plotted against $\Omega$. The final, quasi-equilibrium bar location is highly similar for the same $\Omega$ and interestingly, exhibits an approximately linear dependency between the bar location towards the offshore with increasing $\Omega$. The similarity of the bar location for the same $\Omega$ highlights that storm sequencing does not have a large effect on the final bar location in the present experiments regardless of the previous storm sequence history and antecedent morphologies. However, as shown in figure 7, the time needed for the breaker bar to migrate to its equilibrium location can vary depending on the preceding wave condition and hence, on the disequilibrium of the bar location at the beginning of the wave condition.

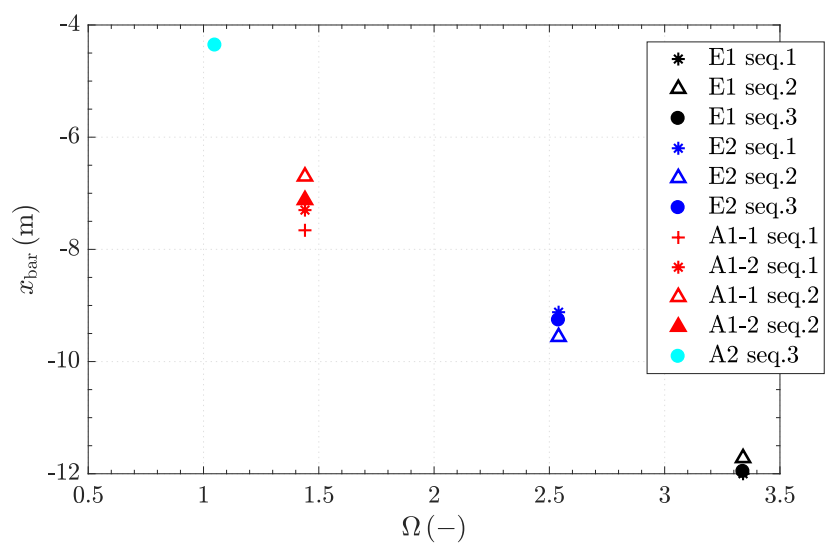

Figure 8: Bar location at the end of each wave condition. 


\subsection{Shoreline evolution}

Figure 9 shows the shoreline location of each measured beach profile of the three sequences. In addition, figure 10 presents the shoreline location at the end of each wave condition against $\Omega$.
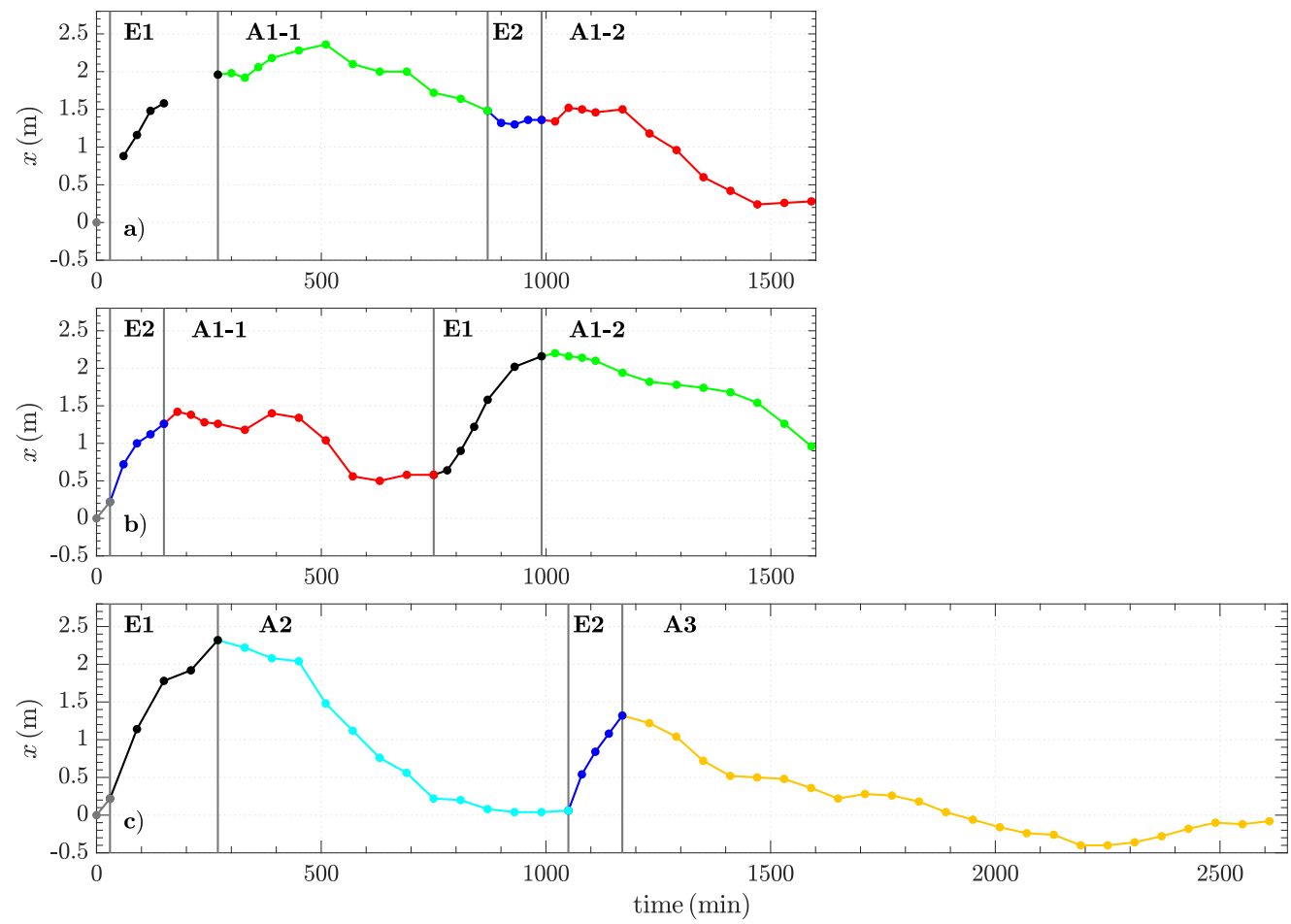

Figure 9: Shoreline location against time in sequence 1 (a), sequence 2 (b), sequence 3 (c).

Similar to the breaker bar location, the shoreline also evolves towards a quasi-equilibrium state under the prevalent wave condition (as can be noted by the reduced shoreline change rate towards the end of most wave conditions). This is particularly evident for condition A1 after E2 as well as for conditions A2 and A3 as the shoreline shows very limited change after a certain duration under these conditions. Also for high energy conditions 


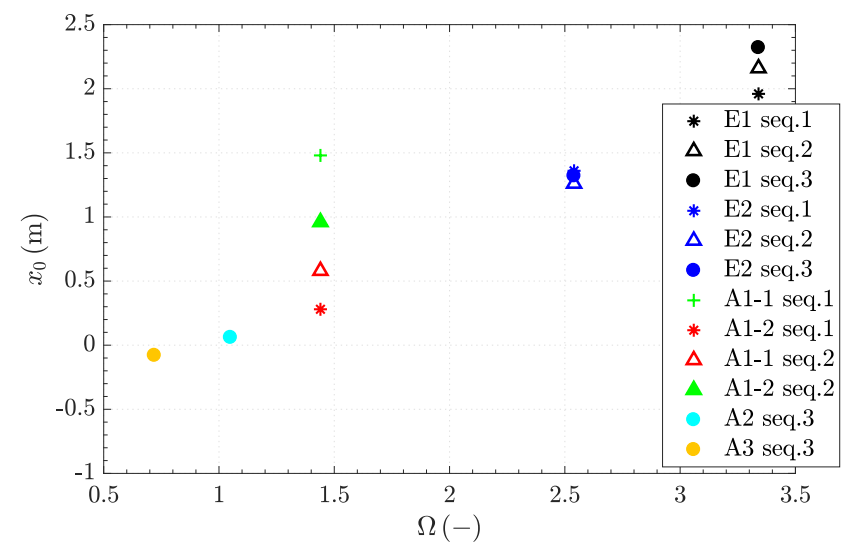

Figure 10: Shoreline location at the end of each wave condition.

shoreline evolution towards an equilibrium location is evident as shoreline recession slows down towards the end of E1 and E2.

The very high energy condition E1 results in a strongly eroded shoreline whereas E2 results in a lesser eroded shoreline compared to E1. These differences in shoreline location have an important effect on the subsequent recovery under A1: in contrast to A1 after E2, the shoreline in A1 after E1 does not reach a quasi-equilibrium location as the time was most likely not sufficient to fully recover the strongly eroded shoreline after E1. This hightlights the importance of the initial morphology and the duration of a wave condition to reach an equilibrium/recovered condition, especially for low energy conditions for which it is known that the profile evolves more slowly compared to storm wave conditions (e.g. Kriebel and Dean, 1993; Morales-Márquez et al., 2018).

The importance of the initial beach morphology is highlighted by a closer examination of the shoreline evolution during condition E2: while the shoreline erodes in both sequences 2 and 3, shoreline change is almost negligible 
in sequence 1. Because the shoreline evolves towards a similar final location under E2 in each sequence, the shoreline change rate is different depending on the sequence and hence, depending on the initial shoreline location of condition E2. In sequence 1, after condition A1-1, the shoreline is close to the final shoreline location of $\mathrm{E} 2$ (i.e. $x_{0} \approx 1.5 \mathrm{~m}$ ) while the shoreline is much more recovered at the beginning of E2 in sequences 2 and 3. Consequently, $\mathrm{E} 2$ in sequence 1 does not promote shoreline erosion as in sequences 2 and 3. This further supports the concept that beach evolution depends on initial beach configuration and wave conditions (e. g. Grasso et al., 2009; Yates et al., 2009; Baldock et al., 2017; Morales-Márquez et al., 2018).

The importance of the wave conditions for shoreline evolution becomes further evident by comparing different low energy conditions that were run from a similar storm profile. A comparison of the shoreline evolution under condition A2 (sequence 3) with condition A1-1 in sequence 1, which were both run after E1, reveals a much higher shoreline recovery rate for A2. At the end of condition A1-1 in sequence 1, the shoreline is not at its quasiequilibrium location because shoreline recovery was not fast enough or because the condition was not run for a sufficient duration. In contrast under A2, the quasi-equilibrium shoreline location $\left(x_{0} \approx 0.1 \mathrm{~m}\right)$ is more onshore located than for A1 but is reached after circa $600 \mathrm{~min}$ which is equivalent to the total duration of A1.

Also condition A3 leads to a quasi-equilibrium shoreline location $\left(x_{0} \approx\right.$ $0 \mathrm{~m}$, after circa $700 \mathrm{~min}$ ). Shoreline recovery occurs more slowly than under A2, despite A3 being a lower energy condition (with a smaller value of $\Omega$ ) which might give reason to expect more pronounced recovery. However, the 
shoreline at the beginning of A2 was further from its equilibrium location which may promote larger shoreline change rates (Yates et al., 2009).

Despite the overall recovery of the shoreline under conditions A1, the shoreline continues to erode in the beginning of most A1 conditions. Baldock et al. (2017) and Birrien et al. (2018) linked beach erosion during the transition from high to lower energy conditions to an onshore shift of the wave breaking location and an associated change towards a more reflective beach state. In the present experiments, this might provide a reason for continued erosion under condition A1 after E1 where waves break close to the inner bar under A1 (see figure 7). However, in the present study initial shoreline erosion under conditions A1 is primarily explained by swash zone processes and the development of a steep berm in the beginning of A1 (as described in section 4.1 along with figure 3 ). The sediment for berm formation originates from the inner surf/lower swash zone by horizontal advection generating initial shoreline erosion under most A1 conditions (e.g. Alsina et al., 2018). This was also previously observed in the field by Weir et al. (2006). Once the berm has developed, it grows in size and expands towards the offshore promoting shoreline recovery. The differences in shoreline evolution in the beginning of A1 starting from a similar erosive profile are found to be related to small variations in the shape of the berm and trough.

\subsection{Sediment transport under different wave conditions}

In this section, results from sediment transport calculations are presented. Figure 11 shows the bulk sediment transport $Q$ as a function of time for wave conditions $\mathrm{E} 2, \mathrm{~A} 1, \mathrm{~A} 2$ and $\mathrm{A} 3$ where $Q$ is computed based on the initial profile at the start of the respective wave condition. For the sediment 
transport computations, the beach profile measurements have to cover the entire active beach which was the case for all conditions except for profiles obtained under condition E1. E1 was the most energetic condition and was found to induce small profile changes offshore that were only covered if an extended profile measurement was performed.

Figure 11 reveals that under the low energy wave conditions (figure 11b, c, d) the bulk sediment transport is normally positive, i. e. onshore directed, and increases with time. Towards the end of the low energy conditions, $Q$ tends towards a relatively stable value. This is specifically evident for condition A3 where the last five data points have a highly similar $Q$ (the last value is considered as an outlier most likely related to a slight shift of the profile which is possibly related to sinking of the wheel of the mechanical profiler when doing the measurement). Note that if $Q$ arrives at a stable value in figure 11, it indicates that there is no further bulk sediment transport during this run, i. e. the profile has evolved to a stable equilibrium condition.

It is interesting to note that in the beginning of conditions A1 after E2 bulk sediment transport is offshore directed (for condition A1-1 seq.2 in figure 11b) or approximately zero (for condition A1-2 seq.1 in figure 11b). This indicates an overall initial erosion of the beach during A1 after E2 (see also figure $9 \mathrm{a}, \mathrm{b})$. In contrast, bulk sediment transport is onshore directed in the beginning of A1 after E1 (A1-1 seq.1 and A1-2 seq.2 in figure 11b). Over longer timescales, however, the differences in $Q$ for the same wave condition and hence, the dependence on the initial beach state, seem to diminish.

For condition E2 a tendency towards a stable $Q$ value can also be noted even though, due to the shorter duration of E2, it is less evident than for 
the low energy conditions (figure 11a). From the profile evolution (see figure 4 , right panels) it was already shown that the profiles under E2 develop towards a stable state (even though the bar and shoreline have not yet reached a fully stable location as known from figures 7 and 9) and can be considered to be close to their quasi-equilibrium. It is interesting to note that reaching this quasi-equilibrium state under E2 corresponds to offshore bulk sediment transport during sequences 2 and 3 but onshore bulk transport during sequence 1.
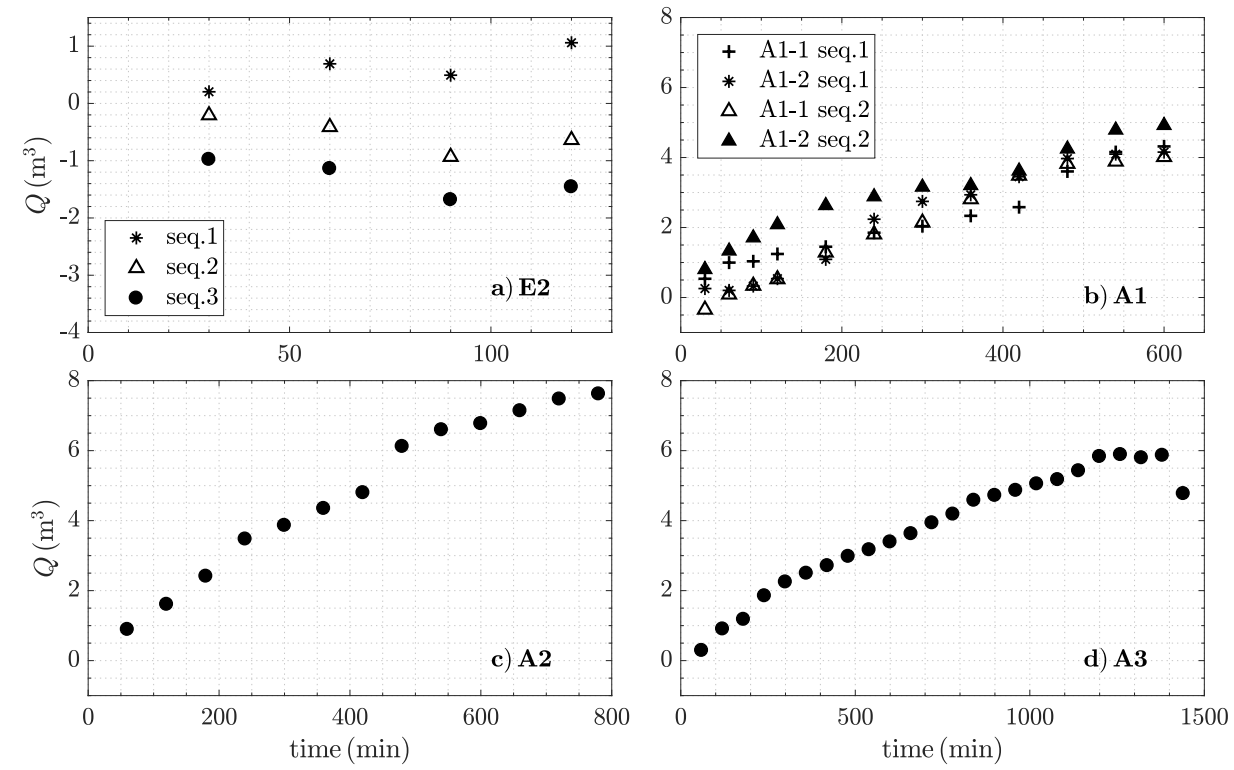

Figure 11: Bulk cross-shore sediment transport $Q$ from the start of each wave condition as a function of time for wave conditions E2 (a), A1 (b), A2 (c) and A3 (d) from different sequences. Note the different durations of the wave conditions resulting in different scales of the abscissas.

Figure 12a shows the bulk sediment transport in quasi-equilibrium, which corresponds to the $Q$ values at the end of each wave condition shown in figure 
11, plotted against $\Omega$. Here, also $Q$ values calculated for the E1 conditions in sequences 2 and 3 can be presented because a complete profile measurement was performed before and after these conditions (covering the closure limits) and as was shown in figure 4, the profile evolves towards equilibrium at the end of E1. For A3, the penultimate value (after $1380 \mathrm{~min}$ ) is shown as equilibrium value.
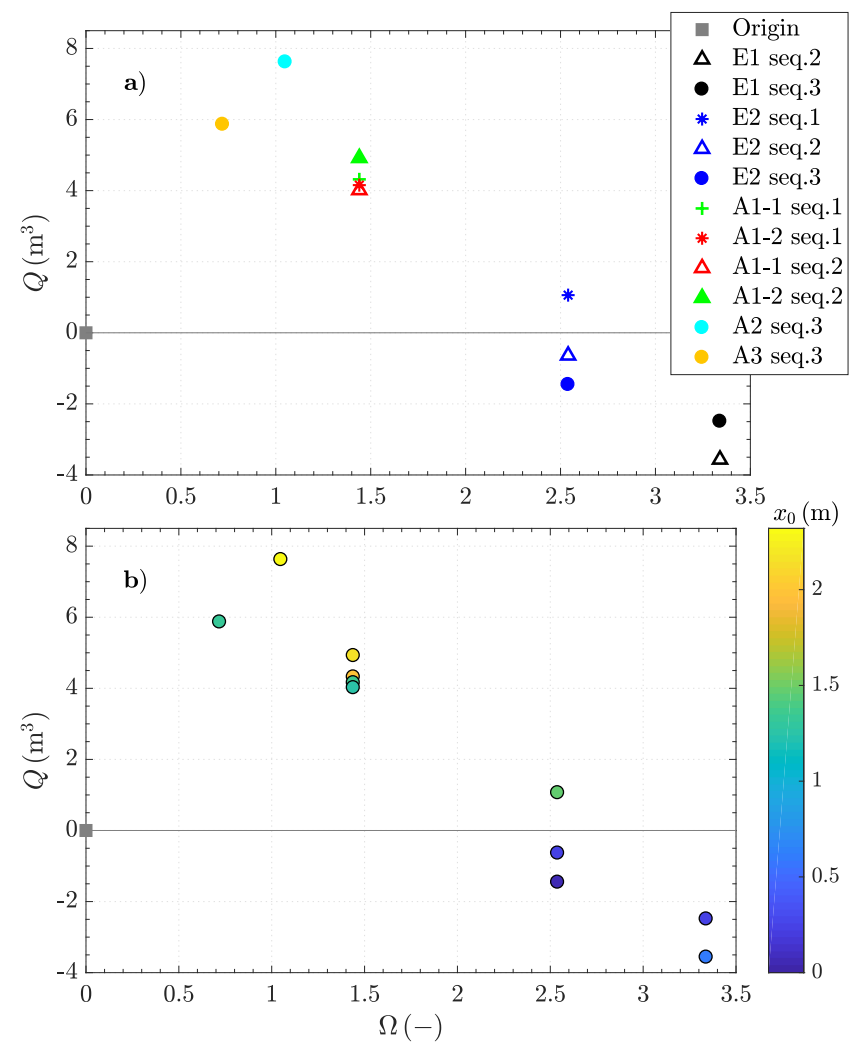

Figure 12: Bulk sediment transport $Q$ from the start of each wave condition at quasiequilibrium. In the bottom panel b the initial shoreline location for each wave condition is indicated with the colour spectrum. Larger (smaller) values of the colour spectrum denote a more eroded (accreted) shoreline at the beginning of the wave condition.

The data presented in figure $12 \mathrm{a}$ show that $Q$ is not necessarily a mono- 
tonic function of $\Omega$ but that lower energy wave conditions, i. e. small values of $\Omega$, can generate larger bulk sediment transport than larger values of $\Omega$. Figure 12a highlights that maximum net onshore sediment transport occurs for A2 despite A3 presenting a lower energy condition (according to $\Omega$ ).

Differences between the bulk transport under the same wave condition (same $\Omega$ ) become evident from figure 12a and are linked to the differences in profile disequilibrium at the beginning of the wave condition. In fact, figure 12a does not account for the initial beach profile which is, however, crucial for the volume of transported sediment. Therefore, figure $12 \mathrm{~b}$ shows the bulk transport $Q$ against $\Omega$ (as in figure 12a) and indicates for each wave condition the initial shoreline location $x_{0}$ with the colour scale. Data points with a similar colour indicate a similar shoreline location at the start of the wave condition and can therefore be compared without the influence of varying initial shorelines.

Baldock et al. (2011) formulated the following $Q-\Omega$-relationship for a given shoreline location based on the beach equilibrium concept:

$$
Q=A\left(\Omega_{e q}\left(x_{0}\right)-\Omega\right) \Omega^{n}
$$

where $\Omega_{e q}\left(x_{0}\right)$ denotes the $\Omega$ value that would result in no/equilibrium sediment transport for the present shoreline location $x_{0}, A\left(\mathrm{~m}^{3}\right)$ is a scaling factor to maintain dimensions and $n$ presents some power.

Baldock et al. (2017) (figure 15a in their paper) exemplified the $Q-\Omega$ relationship for varying values of $\Omega_{e q}\left(x_{0}\right)$. The present data reaffirm this concept by values of $Q$ calculated from experimental data for a similar initial shoreline location (similar colour in figure 12b). 
In line with studies on equilibrium beach evolution, such as Yates et al. (2009) and Baldock et al. (2017), figure 12 evidences that the same wave condition can result in either beach erosion or recovery (corresponding to a negative or positive value of $Q$ ), depending on whether the beach is in a more recovered or eroded state compared to the equilibrium state for these wave conditions. This highlights that the terms erosive and accretive are not necessarily associated with high and low energy wave conditions, respectively, but that they need to be linked to the disequilibrium of the beach for the prevalent wave conditions.

This is most clearly shown by the values of $Q$ for condition E2 in the three sequences: while sediment transport is offshore directed in sequences 2 and 3 , sediment transport is onshore directed in sequence 1. As shown in figure $12 \mathrm{~b}$ and as discussed in section 4.3, the shoreline at the beginning of E2 in sequence 1 is in a less recovered state and hence, closer to the equilibrium shoreline location of E2. Consequently, the shoreline erodes under E2 in sequences 2 and 3 (associated with offshore sediment transport) while no evident shoreline change is observed in sequence 1 where onshore sediment transport occurs.

\section{Discussion}

The similarity of the shoreline and bar location at the end of the same wave conditions, despite different initial morphologies, suggests that the final bar and shoreline location of each wave condition is not much affected by storm sequencing (including storm chronology and hence, the effect of the initial profile). No cumulative effect due to storm sequencing on equilibrium 
bar and shoreline location is observed. The final beach state at the end of each sequence is determined by the last performed wave condition and its duration rather than by storms that occurred previously in the sequence. This is similar to what Vousdoukas et al. (2012) described in their conceptual model that, once an equilibrium beach state is reached, a beach only erodes further if the previous storm power is exceeded. It also supports previous findings from specific field sites on short-term beach evolution under storm sequence forcing by Coco et al. (2014) and Morales-Márquez et al. (2018).

The above findings imply that storm sequencing is important for the change rate of the beach during a storm when the beach does not have sufficient time to recover between two storm events. In this case, a small subsequent storm might even generate beach recovery if the preceding low energy conditions only provided limited recovery (as shown for condition E2 which is further studied in more detail in Eichentopf et al. (2019c)). On the other hand, if the beach is in a more recovered state, more sediment can be eroded during subsequent storm wave conditions. This was similarly highlighted by Yates et al. (2009) and Scott et al. (2016).

The $Q$ - $\Omega$-relationship for a given beach width (Baldock et al., 2011, 2017) is well supported by the present data which provide the advantage of covering a range of wave conditions and initial beach morphologies. It has become evident that bulk sediment transport does not necessarily increase for decreasing values of $\Omega$ but is larger for A2 than for A3 in the present study. This may appear surprising, because condition A3 has a lower $\Omega$ and may therefore be expected to be more accretive than condition A2. However, the larger disequilibrium in the beginning of condition A2 may provide a 
reason for increased bulk transport because a larger disequilibrium is supposed to promote faster beach changes (Yates et al., 2009), provided that the entire beach profile remains active (Scott et al., 2016; Baldock et al., 2017; Biausque and Senechal, 2019). In addition, despite being able to keep the entire beach profile active, the much lower waves of condition A3 may mobilise less sediment and hence, result in reduced recovery rates.

Both the bar and the shoreline evolve towards an equilibrium location that is specific for each wave condition. The timescale for establishing an equilibrium after a change in wave condition is much shorter for the bar (typically within one hour) than for the shoreline (typically a few hours). The experiments were carried out at an approximate geometric scale of 1:2 (Sánchez-Arcilla et al., 2011) and therefore, following Froude scaling, indicative timescales at prototype scale are approximately a factor of $\sqrt{2}$ higher than in the present laboratory setting. Under low energy conditions, the morphological process that importantly contributes to the faster evolution of the bar towards equilibrium compared to the shoreline is the change of the 'active' bar from the outer to the inner bar. This is related to the waves breaking at the inner bar directly from the beginning of conditions A1 and A2. This importantly contributes to the equilibrium location of the bar being reached faster compared to the shoreline and presents a very efficient way of morphological beach adjustment at the present short-term scale, i. e. the former breaker bar does not have to move onshore.

In addition, the faster evolution towards equilibrium of the bar may also be related to the processes driving bar and shoreline evolution which will, however, require future investigations using hydrodynamic measurements. 
While the breaker bar evolution is largely driven by breaking-related processes in the submerged beach, primarily offshore (onshore) sediment transport due to mean return flow (wave non-linearities) (e.g. Hoefel and Elgar, 2003; Mariño-Tapia et al., 2007; Alsina et al., 2016), the shoreline presents the interface between the sub- and emerged beach where processes, such as wave-swash interactions, backwash, and sediment advection, are relevant for sediment transport (e.g. Blenkinsopp et al., 2011; Cáceres and Alsina, 2012; Alsina et al., 2018; van der Zanden et al., 2019). The present findings provide indication that, at least in the present experiments, the processes driving bar evolution tend to occur faster than the processes involved in shoreline evolution. This becomes evident because even for the wave conditions where the secondary bar was not a reason for quick adjustment of the bar location, the equilibrium was reached faster for the bar than for the shoreline (compare, for instance, bar and shoreline evolution during condition A1-2 in sequence 1 in figures $7 \mathrm{a}$ and $9 \mathrm{a}$, respectively).

In terms of a generalisation of the findings on storm sequencing and beach response from the present study, certain aspects have to be considered. Although bichromatic wave conditions in this wave flume were reported to induce similar beach response as random waves (Baldock et al., 2011), the quantitative rate of morphological change to reach equilibrium might be faster for bichromatic waves compared to natural (random) conditions. The details of the bichromatic wave conditions (e. g. number of individual waves per group) can also affect the timescale of morphological evolution. For instance, Alsina et al. (2018) reported that shorter bichromatic wave groups (less individual wave variability) reached equilibrium faster than longer wave groups (more 
individual wave variabiliy).

Moreover, temporal variations in the water level due to tides and surge were not accounted for in the present experiments. Storm peaks coinciding with high tides at tide-dominated environments have the capacity to induce significantly larger beach erosion than expected based on their wave power (Dissanayake et al., 2015c). As a result, a storm that occurs second in the sequence but at high tide may result in further erosion despite similar or even lesser storm power. Following this, the present data have to be considered to compare most closely to a micro-tidal, wave-dominated environment.

Furthermore, as typical for wave flume experiments, the present study focussed on cross-shore beach profile evolution and waves were unidirectional and approached the shore normally. In the field, however, wave directionality and longshore transport can be important for beach evolution. For instance, unusual directions of storms approaching the coast have been reported to have the potential to generate increased beach erosion volumes due to increased wave energy in the nearshore (Mortlock et al., 2017) and they can promote longshore sediment transport.

Extreme storm events, such as storms peaking at high tide or storms of very large power, can generate severe erosion leading to an important change of the active beach profile (Kuriyama and Yanagishima, 2018). This relates, for instance, to erosion of the berm allowing subsequent waves to get further onto the beach resulting in an important narrowing of the beach width and possibly further erosion even under less energetic subsequent storms. This beach response can result in sediment being stranded offshore beyond the depth of closure in a sediment compartment which is unavailable for 
beach recovery under low energy conditions (Scott et al., 2016; Baldock et al., 2017; Ruiz de Alegría-Arzaburu and Vidal-Ruiz, 2018; Biausque and Senechal, 2019). Despite not unusual in natural environments, in the present experiments a change in the active beach state was not observed and sediment eroded during storm conditions could still be mobilised for subequent recovery.

\section{Conclusions}

The influence of storm sequences on cross-shore beach profile evolution with a focus on breaker bar and shoreline evolution was studied based on experiments in a large-scale wave flume. The data analysed in this study comprised beach profile data, wave breaking observations and sediment samples. Three storm sequences were performed as a combination of two storms (a very energetic and a smaller storm event), each followed by a recovery stage (three different types of low energy wave conditions). The duration of the sequences varied between 26 and 43 hours. The results lead to the following conclusions:

- Both the bar and the shoreline evolve towards an equilibrium location that is specific for each type of wave condition regardless of the initial profile morphology. It is mainly a matter of time when the equilibrium condition is reached: while the beach changes fast under high energy wave conditions, the beach responds much more slowly to low energy waves. For both high and low energy conditions, the quasi-equilibrium location establishes much faster for the bar than for the shoreline. 
- The evolution towards an equilibrium beach state implies that no cumulative or enhanced beach erosion due to storm sequencing occurs in the present study. Despite the same cumulative power of each sequence, the final beach state is not determined by previous storms but by the last performed wave conditions. This is consistent with classical equilibrium-type beach models. Initial beach erosion may occur in the beginning of low energy conditions but the effect on the beach state diminishes over larger timescales.

- The initial profile morphology (and hence, storm sequencing) has an important influence on the rate of shoreline change and the induced sediment transport. The initial profile morphology determines how much the beach needs to erode or recover whilst evolving to the new equilibrium state. The same wave condition can generate either shoreline erosion or recovery depending on the initial profile morphology. The change rate of the bar location does not seem much affected by sequencing as the quasi-equilibrium of the bar location is usually reached very fast during each wave condition.

- A non-monotonic $Q-\Omega$-relationship is supported by the various performed wave conditions and the different initial beach morphologies. The largest bulk sediment transport and the fastest shoreline recovery occur for the intermediate low energy condition (A2, $\Omega=1.5)$ which is in line with the $Q-\Omega$-relationship and the large shoreline disequilibrium at the beginning of $\mathrm{A} 2$.

- The breaker bar is almost consistently found at the outer breaking lo- 
cation. When wave conditions change, the breaker bar quickly adjusts to the new breaking location under high energy conditions and more slowly under low energy conditions. For low energy conditions following high energy conditions, the breaking location is usually not much affected by the existing main (largest) bar. If an inner bar exists, waves break close to the inner bar leading to a fast change of the main bar location to the new breaking location under low energy waves. Therefore, the breaker bar should preferably be determined as an active bar as the bar that is in interaction with wave breaking.

- In the present experiments, very low energy wave conditions that are run for a long duration (24 hours) result in an almost steady state, reflective beach profile. The coarsest sediment grains accumulate around the beach step and become finer towards the berm crest and towards the offshore.

The present study has provided evidence of the importance of the initial beach morphology and the beach equilibrium concept even under quickly changing conditions of storm sequences. These results have important implications on coastal protection strategies as storms within sequences do not necessarily result in increased beach erosion. However, site-specific behaviour of natural beaches has to be taken into account and importance should be placed on the potentially severe impact of large storm events, especially when coinciding with high water levels, which may exacerbate the expected beach response during a subsequent storm. 


\section{Acknowledgements}

The experiments described in this work were funded by the European Community's Horizon 2020 Programme through the grant to the budget of the Integrated Infrastructure Initiative HYDRALAB ${ }^{+}$, Contract no. 654110, and were conducted as part of the transnational access project RESIST. SE acknowledges funding from the Department of Civil and Environmental Engineering, Imperial College London, and JvdZ acknowledges funding by NWO-TTW (contract no. 16130). TB acknowledges the support of the Australian Research Council Grant DP14010130 and the Australian Bushfire and Natural Hazards CRC Project 'Resilience to clustered disaster events on the coast - storm surge'. We wish to thank fellow RESIST researchers and the CIEM staff (Joaquim Sospedra, Oscar Galego, Dr. Andrea Marzeddu) for

their contributions to the experiments. We wish to thank Professor Catherine O'Sullivan, Dr. Tingfa Liu, Ken Vinck and the staff from the Geotechnics Laboratory at Imperial College London for their assistance with the sediment grain size analysis. The data supporting the results in this study will be available upon request after completion of the RESIST project.

\section{References}

Almar, R., Castelle, B., Ruessink, B. G., Sénéchal, N., Bonneton, P., Marieu, V., 2010. Two- and three-dimensional double-sandbar system behaviour under intense wave forcing and a meso-macro tidal range. Continental Shelf Research 30, 781-792.

DOI $10.1016 / j . c s r .2010 .02 .001$ 
Alsina, J. M., Cáceres, I., 2011. Sediment suspension events in the inner surf and swash zone. Measurements in large-scale and high-energy wave conditions. Coastal Engineering 58, 657-670.

DOI $10.1016 / j$. coastaleng. 2011.03.002

Alsina, J. M., Cáceres, I., Brocchini, M., Baldock, T. E., 2012. An experimental study on sediment transport and bed evolution under different swash zone morphological conditions. Coastal Engineering 68, 31-43.

DOI $10.1016 / j$. coastaleng. 2012.04.008

Alsina, J. M., Padilla, E. M., Cáceres, I., 2016. Sediment transport and beach profile evolution induced by bi-chromatic wave groups with different group periods. Coastal Engineering 114, 325-340.

DOI $10.1016 / j$. coastaleng. 2016.04.020

Alsina, J. M., van der Zanden, J., Cáceres, I., Ribberink, J. S., 2018. The influence of wave groups and wave-swash interactions on sediment transport and bed evolution in the swash zone. Coastal Engineering 140, 23-42.

DOI $10.1016 / j$. coastaleng. 2018.06.005

Altuhafi, F., O'Sullivan, C., Cavarretta, I., 2013. Analysis of an imagebased method to quantify the size and shape of sand particles. Journal of Geotechnical and Geoenvironmental Engineering 139 (8), 1290-1307.

DOI 10.1061/(ASCE) GT.1943-5606.0000855

Angnuureng, D. B., Almar, R., Senechal, N., Castelle, B., Addo, K. A., Marieu, V., Ranasinghe, R., 2017. Shoreline resilience to individual storms and storm clusters on a meso-macrotidal barred beach. Geomorphology 
290, 265-276.

DOI $10.1016 / j \cdot$ geomorph.2017.04.007

Baldock, T., Manoonvoravong, P., Pham, K. S., 2010. Sediment transport and beach morphodynamics induced by free long waves, bound long waves and wave groups. Coastal Engineering 57, 898-916.

DOI 10.1016/j.coastaleng.2010.05.006

Baldock, T. E., Alsina, J. M., Caceres, I., Vicinanza, D., Contestabile, P., Power, H., Sanchez-Arcilla, A., 2011. Large-scale experiments on beach profile evolution and surf and swash zone sediment transport induced by long waves, wave groups and random waves. Coastal Engineering 58, 214227.

DOI $10.1016 / j$.coastaleng.2010.10.006

Baldock, T. E., Birrien, F., Atkinson, A., Shimamoto, T., Wu, S., Callaghan, D. P., Nielsen, P., 2017. Morphological hysteresis in the evolution of beach profiles under sequences of wave climates - Part 1; observations. Coastal Engineering 128, 92-105.

DOI 10.1016/j.coastaleng. 2017.08.005

Baldock, T. E., Huntley, D. A., Bird, P. A. D., O’Hare, T., Bullock, G. N., 2000. Breakpoint generated surf beat induced by bichromatic wave groups. Coastal Engineering 39, 213-242.

DOI 10.1016/S0378-3839(99)00061-7

Biausque, M., Senechal, N., 2019. Seasonal morphological response of an open sandy beach to winter wave conditions: The example of Biscarrosse 
beach, SW France. Geomorphology 332, 157-169.

DOI 10.1016/j.geomorph.2019.02.009

Birkemeier, W. A., Nicholls, R. J., Lee, G.-h., 1999. Storms, storm groups and nearshore morphological change. In: Proceedings of the Coastal Sediments '99 Conference, New York, USA. pp. 1109-1122.

Birrien, F., Atkinson, A., Shimamoto, T., Baldock, T. E., 2018. Hysteresis in the evolution of beach profile parameters under sequences of wave climates - Part 2; Modelling. Coastal Engineering 133, 13-25.

DOI 10.1016/j.coastaleng.2017.12.001

Blenkinsopp, C. E., Turner, I. L., Masselink, G., Russell, P. E., 2011. Swash zone sediment fluxes: Field observations. Coastal Engineering 58, 28-44. DOI 10.1016/j.coastaleng.2010.08.002

Cáceres, I., Alsina, J. M., 2012. A detailed, event-by-event analysis of suspended sediment concentration in the swash zone. Continental Shelf Research 41, 61-76.

DOI $10.1016 / j . c s r .2012 .04 .004$

Cáceres, I., Grüne, J., Van Rijn, L., Agustín, S.-A., Ahmari, A., Ribberink, J., 2008. Mobile-bed Tests. The Sands Project. pp. 2622-2632.

Castelle, B., Corre, Y., Tomlinson, R., 2008. Can the gold coast beaches withstand extreme events? Geo-Marine Letters 28, 23-30.

DOI $10.1007 / s 00367-007-0086-y$

Coco, G., Senechal, N., Rejas, A., Bryan, K. R., Capo, S., Parisot, J. P., Brown, J. A., MacMahan, J. H. M., 2014. Beach response to a sequence of 
extreme storms. Geomorphology 204, 493-501.

DOI 10.1016/j.geomorph.2013.08.028

Cox, J. C., Pirrello, M. A., 2001. Applying joint probabilities and cumulative effects to estimate storm-induced erosion and shoreline recession. Shore and Beach 69 (2), 5-7.

Dalrymple, R. A., 1992. Prediction of storm/normal beach profiles. Journal of Waterways, Port, Coastal and Ocean Engineering 118 (2), 193-200.

Dean, R. G., 1973. Heuristic models of sand transport in the surf zone. Proceedings of the 1st Australian Conference on Coastal Engineering, Engineering Dynamics in the Coastal Zone, Sydney, Australia, 208-214.

Dette, H. H., Larson, M., Murphy, J., Newe, J., Peters, K., Reniers, A., Steetzel, H., 2002. Application of prototype flume tests for beach nourishment assessment. Coastal Engineering 47, 137-177.

DOI 10.1016/S0378-3839(02)00124-2

Dissanayake, P., Brown, J., Karunarathna, H., 2015a. Impacts of storm chronology on the morphological changes of the Formby beach and dune system, UK. Natural Hazards and Earth System Sciences 15, 1533-1543.

DOI 10.5194/nhess-15-1533-2015

Dissanayake, P., Brown, J., Wisse, P., Karunarathna, H., 2015b. Comparison of storm cluster vs isolated event impacts on beach/dune morphodynamics. Estuarine, Coastal and Shelf Science 164, 301-312.

DOI $10.1016 / \mathrm{j}$.ecss. 2015.07 .040 
Dissanayake, P., Brown, J., Wisse, P., Karunarathna, H., 2015c. Effects of storm clustering on beach/dune evolution. Marine Geology 370, 63-75.

DOI $10.1016 / j \cdot$ margeo.2015.10.010

Eichentopf, S., Baldock, T. E., Cáceres, I., Hurther, D., Karunarathna, H., Postacchini, M., Ranieri, N., van der Zanden, J., Alsina, J. M., 2019b. Influence of storm sequencing and beach recovery on sediment transport and beach resilience (RESIST). In: Proceedings of the HYDRALAB+ Joint User Meeting, Bucharest, Romania.

Eichentopf, S., Cáceres, I., Alsina, J. M., 2018. Breaker bar morphodynamics under erosive and accretive wave conditions in large-scale experiments. Coastal Engineering 138, 36-48.

DOI $10.1016 / j$. coastaleng. 2018.04.010

Eichentopf, S., Karunarathna, H., Alsina, J. M., 2019a. Morphodynamics of sandy beaches under the influence of storm sequences: Current research status and future needs. Water Science and Engineering 12 (3), 221-234.

DOI doi.org/10.1016/j.wse.2019.09.007

Eichentopf, S., van der Zanden, J., Cáceres, I., Alsina, J. M., 2019c. Beach profile evolution towards equilibrium from varying initial morphologies. Journal of Marine Science and Engineering 7 (11), 406.

DOI $10.3390 / j m s e 7110406$

Ferreira, Ó., 2002. Prediction of the impact of storm groups and their importance in coastal evolution. In: Proceedings of the 28th International Conference on Coastal Engineering, Cardiff, Wales. pp. 2725-2730. 
Ferreira, Ó., 2005. Storm Groups versus Extreme Single Storms: Predicted Erosion and Management Consequences. Journal of Coastal Research 42, $221-227$.

Gourlay, M. R., 1968. Beach and dune erosion tests. Tech. rep., Delft Hydraulics Laboratory, Report No. M935/M936, Delft, The Netherlands.

Grasso, F., Michallet, H., Barthélemy, E., 2011. Experimental simulation of shoreface nourishments under storm events: A morphological, hydrodynamic, and sediment grain size analysis. Coastal Engineering 58, 184-193. DOI 10.1016/j.coastaleng.2010.09.007

Grasso, F., Michallet, H., Barthélemy, E., Certain, R., 2009. Physical modeling of intermediate cross-shore beach morphology: Transients and equilibrium states. Journal of Geophysical Research: Oceans 114 (C09001).

DOI $10.1029 / 2009 J C 005308$

Gravois, U., Baldock, T. E., Callaghan, D., Davies, G., Nichol, S., 2018. The effects of storm clustering on storm demand and dune recession at old bar, NSW. In: Proceedings of the 27th NSW Coastal Conference, Merimbula, Australia.

Gravois, U., Baldock, T. E., Hsieh, S., Gomez, C., Callaghan, D. P., 2016. Physical modelling of the effect of storm sequences on beach profile evolution and beach erosion. In: Proceedings of the 25th NSW Coastal Conference, Coffs Harbour, Australia.

Hoefel, F., Elgar, S., 2003. Wave-induced sediment transport and sandbar 
migration. Science 299 (5614), 1885-1887.

DOI 10.1126/science.1081448

Hughes, M. G., Cowell, P. J., 1987. Adjustment of reflective beaches to waves. Journal of Coastal Research 3 (2), 153-167.

Jacobsen, N. G., Fredsoe, J., 2014. Formation and development of a breaker bar under regular waves. Part 2: Sediment transport and morphology. Coastal Engineering 88, 55-68.

DOI $10.1016 / j$. coastaleng.2014.01.015

Karunarathna, H., Pender, D., Ranasinghe, R., Short, A. D., Reeve, D. E., 2014. The effects of storm clustering on beach profile variability. Marine Geology 348, 103-112.

DOI 10.1016/j.margeo.2013.12.007

Kriebel, D. L., Dean, R. G., 1993. Convolution method for time-dependent beach-profile response. Journal of Waterway, Port, Coastal, and Ocean Engineering 119 (2), 204-226.

DOI 10.1061/(ASCE)0733-950X(1993)119:2(204)

Kuriyama, Y., Yanagishima, S., 2018. Regime shifts in the multi-annual evolution of a sandy beach profile. Earth Surface Processes and Landforms 43, 3133-3141.

DOI 10.1002/esp. 4475

Loureiro, C., Ferreira, Ó., Cooper, J. A. G., 2012. Extreme erosion on highenergy embayed beaches: Influence of megarips and storm grouping. Geo- 
morphology 139-140, 155-171.

DOI $10.1016 / j \cdot g e o m o r p h .2011 .10 .013$

Mariño-Tapia, I. J., Russell, P. E., O’Hare, T. J., Davidson, M. A., Huntley, D. A., 2007. Cross-shore sediment transport on natural beaches and its relation to sandbar migration patterns: 1. Field observations and derivation of a transport parameterization. Journal of Geophysical Research: Oceans 112 (C03001).

DOI $10.1029 / 2005$ JC002893

Masselink, G., Ruju, A., Conley, D., Turner, I., Ruessink, G., Matias, A., Thompson, C., Castelle, B., Puleo, J., Citerone, V., Wolters, G., 2016. Large-scale Barrier Dynamics Experiment II (BARDEX II): Experimental design, instrumentation, test program, and data set. Coastal Engineering $113,3-18$.

DOI $10.1016 / \mathrm{j}$.coastaleng.2015.07.009

Miller, J. K., Dean, R. G., 2004. A simple new shoreline change model. Coastal Engineering 51, 531-556.

DOI $10.1016 / j$.coastaleng. 2004.05.006

Miller, R. L., Zeigler, J. M., 1958. A model relating dynamics and sediment pattern in equilibrium in the region of shoaling waves, breaker zone, and foreshore. Journal of Geology 66, 417-441.

Morales-Márquez, V., Orfila, A., Simarro, G., Gómez-Pujol, L., ÁlvarezEllacuría, A., Conti, D., Galán, A., Osorio, A. F., Marcos, M., 2018. Numerical and remote techniques for operational beach management under 
storm group forcing. Natural Hazards and Earth System Sciences 18, 32113223.

DOI 10.5194/nhess-18-3211-2018

Mortlock, T. R., Goodwin, I. D., McAneney, J. K., Roche, K., 2017. The June 2016 Australian East Coast low: Importance of wave direction for coastal erosion assessment. Water 9 (2), 121.

DOI $10.3390 /$ w9020121

Pape, L., Plant, N. G., Ruessink, B. G., 2010. On cross-shore migration and equilibrium states of nearshore sandbars. Journal of Geophysical Research: Earth Surface 115 (F03008).

DOI 10.1029/2009JF001501

Pender, D., Karunarathna, H., 2013. A statistical-process based approach for modelling beach profile variability. Coastal Engineering 81, 19-29.

DOI 10.1016/j.coastaleng.2013.06.006

Phillips, M. S., Harley, M. D., Turner, I. L., Splinter, K. D., Cox, R. J., 2017. Shoreline recovery on wave-dominated sandy coastlines: the role of sandbar morphodynamics and nearshore wave parameters. Marine Geology 385, 146-159.

DOI 10.1016/j.margeo.2017.01.005

Ranasinghe, R., Holman, R., de Schipper, M., Lippmann, T., Wehof, J., Duong, T. M., Roelvink, D., Stive, M., 2012. Quantifying nearshore morphological recovery time scales using argus video imaging: Palm Beach, 
Sydney and Duck, North Carolina. In: Proceedings of the 33rd International Conference on Coastal Engineering, Santander, Spain.

Ruiz de Alegría-Arzaburu, A., Vidal-Ruiz, J. A., 2018. Beach recovery capabilities after El Niño 2015-2016 at Ensenada Beach, Northern Baja California. Ocean Dynamics 68, 749-759.

DOI $10.1007 / \mathrm{s} 10236-018-1164-6$

Sánchez-Arcilla, A., Cáceres, I., 2017. An analysis of nearshore profile and bar development under large scale erosive and accretive waves. Journal of Hydraulic Research.

DOI $10.1080 / 00221686.2017 .1315748$

Sánchez-Arcilla, A., Cáceres, I., van Rijn, L., Grüne, J., 2011. Revisiting mobile bed tests for beach profile dynamics. Coastal Engineering 58, 583593.

DOI $10.1016 / j$. coastaleng. 2011.01 .005

Scott, T., Masselink, G., O'Hare, T., Saulter, A., Poate, T., Russell, P., Davidson, M., Conley, D., 2016. The extreme 2013/2014 winter storms: Beach recovery along the southwest coast of England. Marine Geology $382,224-241$.

DOI 10.1016/j.margeo.2016.10.011

Short, A. D., 1999. Wave-dominated beaches. In: Short, A. D. (Ed.), Handbook of beach and shoreface morphodynamics. Wiley, pp. 151-174.

Splinter, K. D., Carley, J. T., Golshani, A., Tomlinson, R., 2014. A relationship to describe the cumulative impact of storm clusters on beach erosion. 
Coastal Engineering 83, 49-55.

DOI 10.1016/j.coastaleng.2013.10.001

van der Zanden, J., Cáceres, I., Eichentopf, S., Ribberink, J. S., van der Werf, J. J., Alsina, J. M., 2019. Sand transport processes and bed level changes induced by two alternating laboratory swash events. Coastal Engineering 152 (103519).

van der Zanden, J., van der A, D. A., Cáceres, I., Hurther, D., McLelland, S. J., Ribberink, J. S., O’Donoghue, T., 2018. Near-bed turbulent kinetic energy budget under a large-scale plunging breaking wave over a fixed bar. Journal of Geophysical Research: Oceans 123, 1429-1456.

DOI $10.1002 / 2017$ JC013411

van Rijn, L. C., Tonnon, P. K., Walstra, D. J., 2011. Numerical modelling of erosion and accretion of plane sloping beaches at different scales. Coastal Engineering 58, 637-655.

DOI $10.1016 / \mathrm{j}$.coastaleng.2011.01.009

Vousdoukas, M. I., Almeida, L. P. M., Ferreira, Ó., 2012. Beach erosion and recovery during consecutive storms at a steep-sloping, meso-tidal beach. Earth Surface Processes and Landforms 37, 583-593.

DOI 10.1002/esp. 2264

Weir, F. M., Hughes, M. G., Baldock, T. E., 2006. Beach face and berm morphodynamics fronting a coastal lagoon. Geomorphology 82, 331-346.

DOI 10.1016/j.geomorph.2006.05.015 
Wright, L. D., Short, A. D., 1984. Morphodynamic variability of surf zones and beaches: A synthesis. Marine Geology 56, 93-118.

DOI $10.1016 / 0025-3227(84) 90008-2$

Yates, M. L., Guza, R. T., O'Reilly, W. C., 2009. Equilibrium shoreline response: Observations and modeling. Journal of Geophysical Research: Oceans 114 (C09014).

DOI $10.1029 / 2009 J C 005359$ 